Article

\title{
Encapsulation of the Natural Product Tyrosol in Carbohydrate Nanosystems and Study of Their Binding with ctDNA
}

\author{
Antonella Rozaria Nefeli Pontillo ${ }^{1}$, Evangelia Konstanteli ${ }^{1,2} \mathbb{D}$, Maria M. Bairaktari ${ }^{1}$ and Anastasia Detsi ${ }^{1, *(D)}$ \\ 1 Laboratory of Organic Chemistry, Department of Chemical Sciences, School of Chemical Engineering, \\ National Technical University of Athens, 15780 Zografou, Greece; nefelipontillo@gmail.com (A.R.N.P.); \\ e.kwnst@gmail.com (E.K.); maro.bairakt@gmail.com (M.M.B.) \\ 2 Institute of Chemical Biology, National Hellenic Research Foundation, 48 Vassileos Constantinou Avenue, \\ 11635 Athens, Greece \\ * Correspondence: adetsi@chemeng.ntua.gr
}

check for

updates

Citation: Pontillo, A.R.N.;

Konstanteli, E.; Bairaktari, M.M.;

Detsi, A. Encapsulation of the Natural

Product Tyrosol in Carbohydrate Nanosystems and Study of Their Binding with ctDNA. Polymers 2021,

13, 87. https://doi.org/10.3390/ polym13010087

Received: 22 November 2020 Accepted: 24 December 2020 Published: 28 December 2020

Publisher's Note: MDPI stays neutral with regard to jurisdictional clai$\mathrm{ms}$ in published maps and institutional affiliations.

Copyright: (C) 2020 by the authors. Licensee MDPI, Basel, Switzerland. This article is an open access article distributed under the terms and conditions of the Creative Commons Attribution (CC BY) license (https:// creativecommons.org/licenses/by/ $4.0 /)$.

\begin{abstract}
Tyrosol, a natural product present in olive oil and white wine, possesses a wide range of bioactivity. The aim of this study was to optimize the preparation of nanosystems encapsulating tyrosol in carbohydrate matrices and the investigation of their ability to bind with DNA. The first encapsulation matrix of choice was chitosan using the ionic gelation method. The second matrix was $\beta$-cyclodextrin $(\beta C D)$ using the kneading method. Coating of the tyrosol- $\beta C D$ ICs with chitosan resulted in a third nanosystem with very interesting properties. Optimal preparation parameters of each nanosystem were obtained through two three-factor, three-level Box-Behnken experimental designs and statistical analysis of the results. Thereafter, the nanoparticles were evaluated for their physical and thermal characteristics using several techniques (DLS, NMR, FT-IR, DSC, TGA). The study was completed with the investigation of the impact of the encapsulation on the ability of tyrosol to bind to calf thymus DNA. The results revealed that tyrosol and all the studied systems bind to the minor groove of ctDNA. Tyrosol interacts with ctDNA via hydrogen bond formation, as predicted via molecular modeling studies and corroborated by the experiments. The tyrosolchitosan nanosystem does not show any binding to ctDNA whereas the $\beta C D$ inclusion complex shows analogous interaction with that of free tyrosol.
\end{abstract}

Keywords: tyrosol; nanoparticles; Design of Experiment (DoE); chitosan; $\beta$ cyclodextrin; DNA binding

\section{Introduction}

Tyrosol (2-(4-Hydroxyphenyl)ethanol) is a biophenol that is found in olive oil, white wine, beer and vermouth (Figure 1) [1]. Even though tyrosol does not exhibit strong antioxidant activity, it contributes to the cellular defences due to intracellular accumulation [2,3]. Moreover, numerous studies affirm that tyrosol offers neuroprotective and cardioprotective effect and enhances the regulation of the human LDL levels [4,5]. However, its hydrophilic nature impedes its incorporation in lipid substrates and limits its absorption and bioavailability [6].

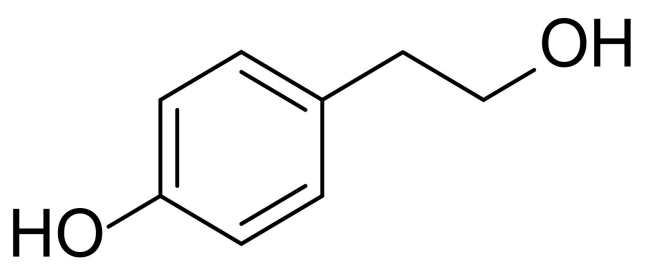

Figure 1. Structure of tyrosol.

Nanoencapsulation of bioactive compounds and pharmaceutical agents in suitable carriers is a very promising technology, as it offers protection and stabilisation of the 
encapsulated compound. Furthermore, the encapsulation of a compound may lead to a controllable and sustained release, thus enhancing its activity. Therefore, this technology is incorporated in a broad range of applications in different fields, such as in medicinal and pharmaceutical science, cosmetics, agrochemical and food industry [7-10].

$\beta$-cyclodextrin $(\beta C D)$ is a truncated cone-shaped oligosaccharide, with a hydrophobic inner cavity and a hydrophilic outer surface [11]. Small, hydrophobic molecules can be entrapped in the cavity forming an inclusion complex (IC), increasing their solubility, while more hydrophilic compounds can be bound on the external surface [12-14].

Chitosan (CS) is a naturally occurring polymer widely used as a nanocarrier. It is nontoxic, biocompatible and biodegradable and is recognised as Generally Recognised as Safe (GRAS) by the Food and Drug Administration (FDA) $[15,16]$. The process of encapsulation in chitosan nanoparticles (NPs) has been extensively studied and various techniques have been reported. The nature of the polymer permits the encapsulation of small or larger molecules, natural products like plant extracts and essential oils, or even other nanosystems [17-19].

The properties of the particulate system are defined by the selected carrier and preparation process. Therefore, the ability to design and engineer the experimental process in order to obtain desirable results is an asset for any application. To that end, experimental design and statistical analysis are implemented. Box-Behnken design (BBD) is a Response Surface Methodology (RSM) that enables the multivariate optimisation of a quadratic model [20-22].

Intercalators and groove binders are a class of compounds that interact with the doublestranded DNA. Many anticancer drugs, such as anthracyclines, interact with the DNA through intercalation between adjacent base pairs perpendicularly to the axis of the helix. Many substituents in the intercalator molecule can greatly influence the binding mechanism, the geometry of the ligand-DNA complex and the selectivity of the sequence [23,24].

The interactions between the various cyclodextrins and DNA have yet to be completely identified; however, they are of utmost importance as there are many marketed formulations that contain cyclodextrins. Modified cationic cyclodextrins are known to interact with DNA for gene therapy applications while a strong interaction of a $\beta C D$ complex was proved to be formed with DNA as the ribose and phosphate groups of the DNA exert a stabilizing effect by forming H-bonds with the outer surface of CD $[25,26]$.

The aim of this study was to develop and optimize the encapsulation process of tyrosol in nanosystems using different matrices namely: chitosan (TYR/CS), $\beta C D$ (TYR- $\beta$ CD) as well as in the combined system of $\beta C D / C S$ (TYR- $\beta C D / C S)$. The kneading method was used for the preparation of the inclusion complex of tyrosol with $\beta C D$ (TYR- $\beta C D)$ and ionic gelation for the synthesis of the chitosan nanoparticles. The process optimisation was performed in both cases using a three-factor three-level BBD. The independent variables were set as the initial concentration of the polymer, the loading capacity of TYR or the TYR- $\beta C D$ inclusion complex and the amount of the cross-linking agent. The examined range was elicited from literature data and data from preliminary experiments.

Complete characterisation of the systems was performed by various methods and techniques, such as Nuclear Magnetic Resonance Spectroscopy (NMR), Infrared Spectroscopy (FT-IR), antioxidant activity determination by the DPPH method, Dynamic Light Scattering (DLS) for the measurement of size, polydispersity index and $\zeta$-potential, Thermogravimetric Analysis (TGA) and Scanning Electron Microscopy (SEM). Finally, the effect of the encapsulation matrix on the ability of tyrosol to interact with Calf-thymus DNA (ctDNA) was investigated.

\section{Materials and Methods}

\subsection{Materials}

Tyrosol was purchased from Fluorochem (Hadfield, Derbyshire, UK), $\beta$-Cyclodextrin in an assay $\geq 99 \%$ (HPLC) was obtained from Fluka (Buchs, Switzerland) and Chitosan (5-20 mPa $\cdot \mathrm{s}, 0.5 \%$ in $0.5 \%$ Acetic Acid at $20^{\circ} \mathrm{C}$ ) from TCI (TCI (Shanghai, China). Tween 80, 
Tris Base, rhodamine B and deoxyribonucleic acid sodium salt, calf thymus were purchased from Alfa Aesar (Ward Hill, MA, USA) and Sodium Tripolyphosphate from Acros Organics (Morris Plains, NJ, USA). For all the experiments double-deionised water was used.

\subsection{Synthesis of Nanoparticles}

\subsubsection{Preparation of Inclusion Complexes of Tyrosol with $\beta C D$ (TYR- $\beta C D)$}

The kneading method was used for the preparation of the inclusion complex. Briefly, equimolar quantities of $\beta C D(569 \mathrm{mg})$ and TYR $(70 \mathrm{mg})$ were mixed in an agate mortar and pestle with minimum amount of the solvent $\left(\mathrm{H}_{2} \mathrm{O}: \mathrm{EtOH} 7: 3 \mathrm{v} / \mathrm{v}\right)$ for $30 \mathrm{~min}$. The paste was dried to constant weight in a high vacuum pump [27].

\subsubsection{Encapsulation of Tyrosol in Chitosan Nanoparticles (TYR/CS)}

In a $1 \%$ aqueous acetic acid solution, $0.05 \%, 0.2 \%$ or $0.35 \%$ CS was fully dissolved. Then, an equal to CS amount of emulsifier Tween 80 is added and left to stir at room temperature overnight until complete dissolution. In $5 \mathrm{~mL}$ of the occurring solution $2.5,10$ or $17.5 \mathrm{mg}$ of tyrosol was added and the solution was left to stir until total dissolution. Then $1 \mathrm{~mL}$ of TPP solution of concentration $0.42,1.67$ or $0.35 \mathrm{mg} / \mathrm{mL}$ was added dropwise. The sample was left under magnetic stirring at $700 \mathrm{rpm}$, for $10 \mathrm{~min}$ at $25^{\circ} \mathrm{C}$. The nanoparticles were centrifuged at 30,000 rpm for $45 \mathrm{~min}$. The sediment was dispersed and washed with two more consecutive centrifugations. Finally, the nanoparticles were freeze dried and stored in a desiccator.

\subsubsection{Coating of the Tyrosol- $\beta C D$ Inclusion Complexes with Chitosan (TYR- $\beta$ CD/CS)}

For the synthesis of TYR- $\beta C D / C S$ nanoparticles, the procedure described in "Section 2.2.2" was followed, adding TYR- $\beta$ CD instead of tyrosol. For preparation of blank chitosan nanoparticles, in $5 \mathrm{~mL}$ of $0.2 \%$ chitosan, $1 \mathrm{~mL}$ of TPP solution $1.67 \mathrm{mg} / \mathrm{mL}$ was added and the solution was left to stir for $10 \mathrm{~min}$.

\subsection{Design of Experiments (DoE)}

Two experimental designs were conducted to optimize the processes for preparation of TYR/CS and TYR- $\beta$ CD/CS nanoparticles. Design-Expert ${ }^{\circledR}$ in trial version (Version 12, Stat-Ease, Inc., Minneapolis, MN, USA) was used.

Three factors at three levels were selected to control the size (response $R_{1}$ ) and $\zeta$ potential (response $\mathrm{R}_{2}$ ) of the nanosystem. Factor $\mathrm{A}$ was the concentration of the chitosan solution, factor B was the mg of TPP and factor C the amount of tyrosol for the TYR/CS nanosystem or of the inclusion complex for the TYR- $\beta$ CD/CS system.

Factors' levels and their normalised values are shown in Table 1 . Central Point $(0,0,0)$ was repeated three times, and a total of 15 runs were performed for each set.

Table 1. Factors, level and responses of the DoE studies.

\begin{tabular}{|c|c|c|c|c|c|c|c|}
\hline & \multirow{2}{*}{ Factors } & \multicolumn{3}{|c|}{ Levels } & \multicolumn{2}{|r|}{ Responses } & \multirow{3}{*}{$\begin{array}{l}\text { Constrains } \\
\text { Minimize }\end{array}$} \\
\hline & & -1 & 0 & +1 & \multirow{2}{*}{$\mathrm{R}_{1}$} & \multirow{2}{*}{ Size (nm) } & \\
\hline A & $\mathrm{CS}(\% \mathrm{w} / \mathrm{v})$ & 0.05 & 0.20 & 0.35 & & & \\
\hline $\mathrm{B}$ & TPP (mg) & 0.42 & 1.67 & 2.92 & & & \\
\hline $\mathrm{C}$ & $\begin{array}{c}\text { (i) TYR (mg) } \\
\text { (ii) } \text { TYR- } \beta C D(\mathrm{mg})\end{array}$ & 2.5 & 10.0 & 17.5 & $\mathrm{R}_{2}$ & $\zeta$-potential $(\mathrm{mV})$ & Maximize \\
\hline
\end{tabular}

The data obtained were analysed with Analysis of Variance (ANOVA). Linear, secondorder and quadratic models were evaluated for all responses and in terms of statistical significance, $R^{2}$ values and the deviation of the predicted to the experimentally obtained results.

The confidence level was set at $95 \%$ and $p$-values $\leq 0.05$ to determine statistically significant factors. 


\subsection{Characterisation of the Nanoparticles}

\subsubsection{Dynamic Light Scattering (DLS)}

The measurements for size, polydispersity index (PDI) and $\zeta$-potential were performed in a Zetasizer Nano ZS, Malvern Instruments Ltd. (Malvern, UK) using a cuvette DTS1070. The results were analysed with the Zetasizer 7.12, Malvern Instruments Ltd. Software.

For TYR- $\beta C D, 1 \mathrm{mg}$ of the dried sample was dissolved in $4 \mathrm{~mL}$ of water and was fully dispersed with 2 min ultrasound at a 2210 Ultrasonic Bath, Branson. DLS measurements of the TYR/CS and TYR- $\beta$ CD/CS samples were conducted by diluting $1 \mathrm{~mL}$ of freshly made sample in $1 \mathrm{~mL}$ of water.

\subsubsection{Encapsulation Efficiency (EE\%) and Loading Capacity (LC\%)}

After ultracentrifugation, the quantification of free tyrosol in the supernatant was performed using UV-Vis spectroscopy.

$$
\begin{gathered}
E E \%=\frac{\text { Total TYR }(m g)-\text { TYR in supernatant }(m g)}{\text { Total TYR }(m g)} \times 100 \\
L C \%=[\text { Total encapsulated }(m g) / \text { total nanoparticles weight }(m g)] \times 100
\end{gathered}
$$

\subsubsection{Release Study}

The release profile of tyrosol was investigated by determining the quantity of tyrosol released form the nanosystem at given time intervals. For that reason, $50 \mathrm{mg}$ of the each nanosystem were dissolved in a $12 \mathrm{~mL}$ solution of aqueous $1 \%$ acetic acid $(6 \mathrm{~mL})$ and $6 \mathrm{~mL}$ DMSO and were stirred at $37^{\circ} \mathrm{C}$ at $100 \mathrm{rpm}$. At specific time intervals, $0.5 \mathrm{~mL}$ of sample was obtained and filtered through a $0.45 \mu \mathrm{m}$ pore syringe filter and analysed by UV-Vis spectroscopy. Each time $0.5 \mathrm{~mL}$ of fresh solvent was added to the solution

\subsubsection{Fourier Transform Infrared Spectroscopy (FTIR)}

$\mathrm{KBr}$ pellets containing the dried sample were prepared with hydraulic pellet press. The FT-IR spectra were recorded with a JASCO FT/IR-4200 spectrometer (Japan Spectroscopic Company, Tokyo, Japan).

\subsubsection{Nuclear Magnetic Resonance Spectroscopy (NMR)}

${ }^{1} \mathrm{H}$ NMR spectrum of TYR- $\beta$ CD IC was obtained to determine the host-guest interactions. The spectra were obtained on a Varian V $600 \mathrm{MHz}$ instrument (National Hellenic Research Foundation, Institute of Chemical Biology, Athens, Greece). The inclusion complex was dissolved in deuterium oxide $\left(\mathrm{D}_{2} \mathrm{O}\right)$.

\subsubsection{Thermal Characterisation}

Thermal characterisation of the dried samples was performed with Differential Scanning Calorimetry (DSC) with a DSC 1 STARe System device (Mettler Toledo, Columbus, $\mathrm{OH}$, USA) at temperature range from $20^{\circ} \mathrm{C}$ to $350{ }^{\circ} \mathrm{C}$ with heating rate $10{ }^{\circ} \mathrm{C} / \mathrm{min}$, under nitrogen gas flow $20 \mathrm{~mL} / \mathrm{min}$ and Thermogravimetric Analysis (TGA) the TGA/DSC 1 STARe System Thermobalance (Mettler Toledo, Columbus, OH, USA) at $25{ }^{\circ} \mathrm{C}-600{ }^{\circ} \mathrm{C}$, with heating rate $10^{\circ} \mathrm{C} / \mathrm{min}$, under nitrogen gas flow $10 \mathrm{~mL} / \mathrm{min}$.

\subsection{Molecular Docking}

The study of the interaction mode and binding affinity docking studies has been performed with the crystal structure of the DNA (PDB ID: 1bna), was obtained from the RSCB protein Data Bank. The optimisation of the docking parameters was performed using AutoDock Vina software (The Scripps Research Institute, La Jolla, CA, USA) and implemented empirical free energy function. Only polar hydrogens were added to the DNA in AutoDock Tools [28]. Finally, the image has been generated using PyMol software. The name and the number of nucleotides were designed according to PyMol software. 


\subsection{DNA Binding Studies Using UV-Vis Spectroscopy}

Lyophilised Calf-thymus DNA (ctDNA) was dissolved in Tris- $\mathrm{HCl}$ buffer solution of concentration $10 \mathrm{mM}$ and $\mathrm{pH} 7.4$, and left overnight at $4{ }^{\circ} \mathrm{C}$. Then, $1 \mathrm{mg}$ ctDNA was dissolved in $1 \mathrm{~mL}$ buffer and the concentration was determined from the absorbance at $260 \mathrm{~nm}$ using an extinction coefficient of $6600 \mathrm{M}^{-1} \mathrm{~cm}^{-1}$ [29]. Tyrosol, $\beta C D, C S, T Y R-\beta C D$, TYR- $\beta C D / C S$, TYR/CS and Rhodamine $B$ were dissolved in the buffer to a concentration of $10 \mathrm{mM}$ for tyrosol or Rhodamine B or $2 \mathrm{mg} / \mathrm{mL}$ for the two carriers and all the nanosystems, which were then used as the stock solution for the preparation of the concentration of $100 \mu \mathrm{M}$. Afterwards, various concentrations $(0-100 \mu \mathrm{M})$ of ctDNA were added to the prepared solutions which were incubated for $5 \mathrm{~min}$ and $30 \mathrm{~min}$ at $37^{\circ} \mathrm{C}$. Absorption spectra were measured using a JASCO double beam V-770 UV-Vis/NIR spectrophotometer in range of $230-400 \mathrm{~nm}$.

\section{Results}

3.1. DoE for the TYR/CS Preparation Process

The measured responses for the TYR/CS nanoparticles are presented in Table 2.

Table 2. Experimental data of TYR/CS nanosystem and obtained results.

\begin{tabular}{ccccccc}
\hline & & \multicolumn{3}{c}{ Factors } & \multicolumn{2}{c}{ Responses } \\
\cline { 3 - 7 } No & Coded Name & A & B & C & $\begin{array}{c}\text { R1 } \\
\text { Size (nm) }\end{array}$ & $\begin{array}{c}\text { R2 } \\
\text { C-Potential (mV) }\end{array}$ \\
\hline 1 & TYR/CS 54 & 1 & 0 & -1 & 168.8 & 41.6 \\
\hline 2 & TYR/CS 52 & 1 & -1 & 0 & 574.6 & 46.4 \\
\hline 3 & TYR/CS 49 & -1 & 1 & 0 & precipitated & 4.3 \\
\hline 4 & TYR/CS 50 & 0 & -1 & -1 & 679.6 & 41.7 \\
\hline 5 & TYR/CS 77 & 0 & 0 & 0 & 127.2 & 24.8 \\
\hline 6 & TYR/CS 57 & 0 & 1 & -1 & 139.4 & 32.0 \\
\hline 7 & TYR/CS 45 & 0 & -1 & 1 & 474.8 & 36.4 \\
\hline 8 & TYR/CS 53 & 1 & 0 & 1 & 199.3 & 43.3 \\
\hline 9 & TYR/CS 42 & 0 & 0 & 0 & 139.8 & 36.4 \\
\hline 10 & TYR/CS 51 & 0 & 0 & 0 & 115.3 & 35.5 \\
\hline 11 & TYR/CS 56 & 0 & 1 & 1 & 148.9 & 37.5 \\
\hline 12 & TYR/CS 47 & -1 & -1 & 0 & 393.4 & 28.6 \\
\hline 13 & TYR/CS 43 & -1 & 0 & -1 & precipitated & 8.7 \\
\hline 14 & TYR/CS 46 & -1 & 0 & 1 & precipitated & 12.7 \\
\hline 15 & TYR/CS 55 & 1 & 1 & 0 & 206.1 & 37.0 \\
\hline
\end{tabular}

From the table above, it can be observed that the size of the occurring nanoparticles ranged from $115.3 \mathrm{~nm}$ at central point to $679.6 \mathrm{~nm}$ except for points $(-1,1,0),(-1,0,1)$ and $(-1,0,-1)$ in which the particles were over $3 \mu \mathrm{m}$ and precipitated.

$\zeta$-potential was positive in all cases and ranged from 4.3 to $46.4 \mathrm{mV}$. As chitosan is a cationic polymer at acidic environments, highly positive $\zeta$-potential is expected, and is indicative of its stability in dispersion. However, the presence of the polyanion TPP manages to reduce the value, by interacting with the protonated amino groups.

Particles in the micro scale were observed only in three points in all of which the concentration of chitosan was at the low level while the concentration of TPP was on its medium or high level. Hence, it can be deduced that when the ratio of chitosan to TPP is low, there is accumulation of the cross-linker in the particles surface, which can also be confirmed by the low $\zeta$-potential. On the other hand, increase in the particles' 
size is also observed when the ratio of chitosan to TPP is high, as it occurs from points $(1,-1,0),(0,-1,-1)$ and $(0,-1,1)$. This could be attributed to an excess of chitosan in the particles surface resulting in insufficient cross-linking of the polymer and low crosslinking density between the polymer and the cross-linking agent. The high $\zeta$-potential of those points confirms the existence of protonated amino groups on the surface of the NPs. Moreover, increased concentration of chitosan leads in decreased intermolecular distance and increased intermolecular hydrogen bonding between the polymeric chains [30-34].

$3 \mathrm{D}$ surface plots of $R_{1}$ were designed (Figure 2), and statistical analysis of the results was performed. A Reduced Quadratic Model better described the results (Equation (3)) and was found to be statistically significant ( $p$-value 0.0012 ). Factors $A, B, A B, A^{2}$ were found to be statistically significant, verifying the observation that the size of the nanoparticles depends both on the amount of chitosan and the interaction with the crosslinking agent TPP. The Model F-value was calculated to be 9.43, indicating a significant model.

The coded equation that describes the size response is:

$$
R_{1}=-85.74-2666.41 A+1450.25 B+162.06 C-3301.28 A B+2674.75 A^{2}+729.22 B^{2}
$$

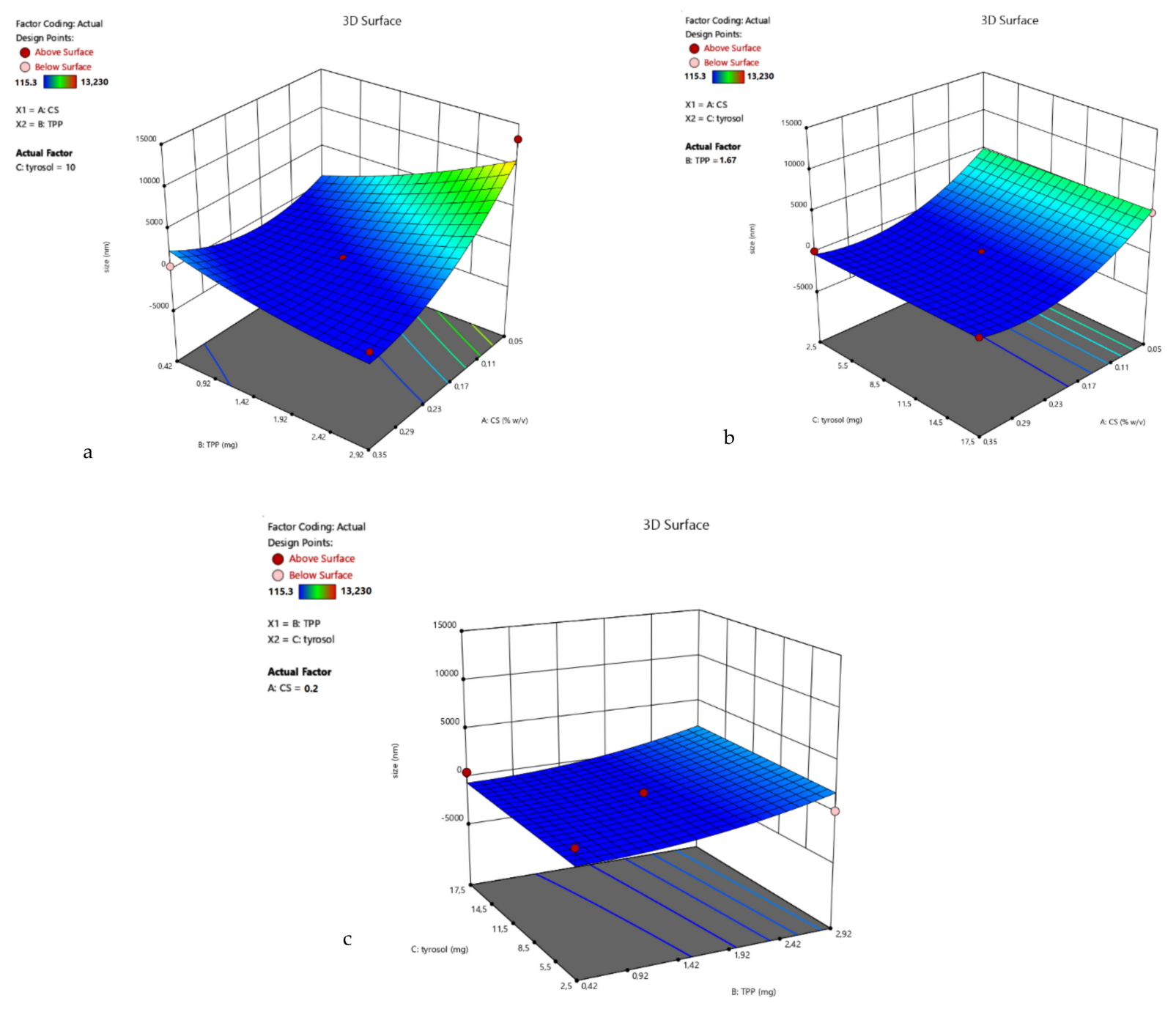

Figure 2. 3D surface plot of response R1 of TYR/CS system (a) CS Vs TPP (tyrosol: $10 \mathrm{mg}$ ) (b) CS Vs TYR (TPP: $1.67 \mathrm{mg}$ ) (c) TPP Vs TYR (CS: 0.2\%). 
For the $\zeta$-potential response, the linear model (Equation (4)) best described the relation between the experiment data of $R_{2}$ and the model F-value was 9.64. The 3D surface plots of $R_{2}$ are presented in Figure 3.

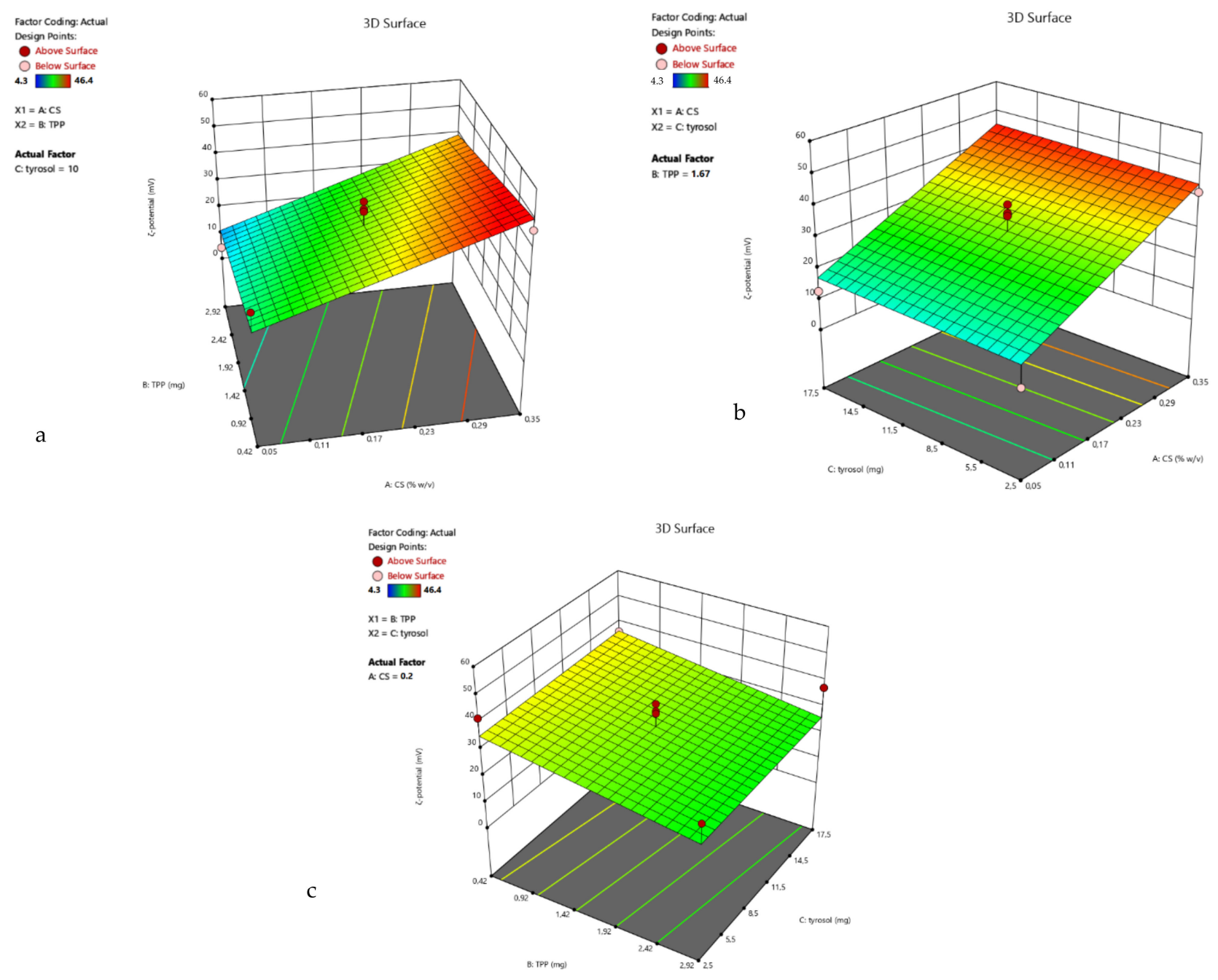

Figure 3. 3D surface plot of response $\mathrm{R}_{2}$ of TYR/CS system (a) CS Vs TPP (tyrosol: $10 \mathrm{mg}$ ) (b) CS Vs TYR (TPP: $1.67 \mathrm{mg}$ ) (c) TPP Vs TYR (CS: 0.2\%).

The coded equation that describes the $\zeta$-potential-response is:

$$
\mathrm{R}_{2}=30.64+14.25 \mathrm{~A}-5.29 \mathrm{~B}+0.74 \mathrm{C}
$$

Table 3 summarises the significance of each factor for the responses $R_{1}$ and $R_{2}$ of the TYR/CS nanosystem.

Optimal preparation conditions for TYR/CS nanoparticles are found to be close to the Central Point (CP) values of factors $B$ and $C$ and in the range $0.2-0.35 \%$ for the CS concentration.

Those results are in accordance with literature. Shah et al. [31], prepared CS nanoparticles loaded with quetiapine fumarate sized between 140 and $487 \mathrm{~nm}$. The optimal preparation conditions were CS concentration $0.1 \%$ and CS:TPP ratio $4.8: 1$, with stirring time $15 \mathrm{~min}$ at $700 \mathrm{rpm}$ and resulted in nanoparticles of size $131.08 \mathrm{~nm}$ with $\zeta$-potential $34.4 \mathrm{mV}$. Delan et al. [30] used BBD for the optimisation of the synthesis of chitosan nanoparticles loaded with the anionic and lipophilic drug simvastatin. It was found that the best CS concentration was $0.34 \%$ and the CS:TPP ratio was 3:1, leading to nanoparticles of size 
$106 \mathrm{~nm}$ and $\zeta$-potential $43.3 \mathrm{mv}$. Sharma et al. [34] ran a four-factor, three-level BBD to assess the process of synthesis of Carvedilol loaded CS nanoparticles. In their research, optimum CS concentration was found to be $0.262 \%$ and the nanoparticle size was measured with TEM $102.12 \mathrm{~nm}$.

Table 3. Significance of each factor equation model terms of the TYR/CS system.

\begin{tabular}{ccc}
\hline \multirow{2}{*}{ Factor } & \multicolumn{2}{c}{$p$-Value } \\
\cline { 2 - 3 } & $\mathbf{R}$ 1 & R2 \\
\hline Model & 0.0012 & 0.0013 \\
\hline A & 0.0010 & 0.0002 \\
\hline B & 0.0309 & 0.0843 \\
\hline C & 0.7848 & 0.7984 \\
\hline AB & 0.0024 & - \\
\hline $\mathrm{A}^{2}$ & 0.0072 & - \\
\hline $\mathrm{B}^{2}$ & 0.3807 & - \\
\hline $\mathrm{R}^{2}$ & 0.850 & 0.6899 \\
\hline Adjusted $\mathrm{R}^{2}$ & 0.760 & 0.6184 \\
\hline Adeq Precision & 11.385 & 10.0663 \\
\hline
\end{tabular}

\subsection{DoE for $T Y R-\beta C D / C S$}

The aqueous dispersion of the inclusion complex of tyrosol with $\beta C D$ is formed by nanoparticles of size $478.1 \mathrm{~nm}$ with a negative, almost neutral $\zeta$-potential of $-7.18 \mathrm{mV}$. The entrapment of the inclusion complex into the chains of chitosan reversed the $\zeta$-potential, due to the presence of chitosan in the outer layer of the inclusion complexes. Furthermore, in most of the 15 runs of the experimental design, the obtained particles were significantly smaller than the inclusion complex. This could be attributed to the strong electrostatic interaction between the oppositely charged carriers, which could separate agglomerations.

From the data in Table 4, it can be observed that the measured sizes ranged from $132.6 \mathrm{~nm}$ to over $3 \mu \mathrm{m}$, which precipitate, while the $\zeta$-potential ranged from 4.8 to $46.5 \mathrm{mV}$.

The lowest result for $R_{1}$ is at the point $(0,+1,-1)$, but at the $C P$, the size is also very close (average is $190.5 \mathrm{~nm}$ ). In this design, it can also be observed that the chitosan-toTPP ratio has a strong impact on the particles' size and $\zeta$-potential. Therefore, for points $(-1,1,0),(-1,0,-1)$ and $(-1,0,1)$, the particles precipitate, and the $\zeta$-potential is very low. Moreover, from the $3 \mathrm{D}$ surface plot of the response $\mathrm{R}_{1}$ (Figure 4 ), the size tends to decrease when the concentration of CS increases.

According to the mathematical analysis, the Reduced Quadratic Model was the most suitable for describing this response $(F=12.08)$. The coded equation (Equation (5)) that describes the system is:

$$
R_{1}=-185.97-3350.14 A+1093.59 B-226.53 C-2506.92 A B+3392.22 A^{2}+906.57 C^{2},
$$

The $\zeta$-potential values range from 4.8 to $46.5 \mathrm{mV}$ for the TYR- $\beta \mathrm{CD} / \mathrm{CS}$ system.

Response $\mathrm{R}_{2}$ is best described by the quadratic model, with F-value $=24.02$. The coded equation (Equation (6)) of the model is as follows:

$$
R_{2}=25.04+13.11 A-4.30 B+2.54 C+2.18 A B+1.50 A C-1.03 B C-6.72 A^{2}+7.21 B^{2}+5.98 C^{2},
$$

The 3D surface plots of $R_{2}$ are presented in Figure 5 .

Table 5 summarises the significance of each factor for the responses $R_{1}$ and $R_{2}$ of the TYR- $\beta$ CD/CS nanosystem. 
Table 4. Experimental data of TYR- $\beta C D / C S$ nanosystem and obtained results.

\begin{tabular}{|c|c|c|c|c|c|c|}
\hline \multirow{2}{*}{ Run } & \multirow{2}{*}{ Coded Name } & \multicolumn{3}{|c|}{ Factors } & \multicolumn{2}{|c|}{ Responses } \\
\hline & & A & B & $\mathrm{C}$ & $\mathbf{R}_{\mathbf{1}}$ & $\mathbf{R}_{2}$ \\
\hline 1 & TYR- $\beta$ CD/CS 67 & 0 & -1 & -1 & 364.8 & 36.9 \\
\hline 2 & TYR- $\beta$ CD/CS 78 & 0 & 0 & 0 & 159.0 & 28.7 \\
\hline 3 & TYR- $\beta$ CD/CS 66 & -1 & +1 & 0 & precipitated & 4.8 \\
\hline 4 & TYR- $\beta C D / C S 73$ & 0 & +1 & +1 & 142.2 & 37.5 \\
\hline 5 & TYR- $\beta$ CD/CS 70 & +1 & 0 & +1 & 231.0 & 39.9 \\
\hline 6 & TYR- $\beta$ CD/CS 68 & 0 & 0 & 0 & 162.5 & 21.2 \\
\hline 7 & TYR- $\beta C D / C S 71$ & +1 & 0 & -1 & 190.3 & 34.3 \\
\hline 8 & TYR- $\beta C D / C S 64$ & -1 & -1 & 0 & 276.7 & 19.4 \\
\hline 9 & TYR- $\beta C D / C S 72$ & +1 & +1 & 0 & 221.3 & 36.0 \\
\hline 10 & TYR- $\beta$ CD/CS 69 & +1 & -1 & 0 & 595.0 & 41.9 \\
\hline 11 & TYR- $\beta$ CD/CS 79 & 0 & 0 & 0 & 141.5 & 27.8 \\
\hline 12 & TYR- $\beta$ CD /CS 62 & 0 & -1 & +1 & 441.5 & 46.5 \\
\hline 13 & TYR- $\beta$ CD /CS 61 & -1 & 0 & -1 & precipitated & 11.7 \\
\hline 14 & TYR- $\beta$ CD/CS 63 & -1 & 0 & +1 & precipitated & 11.3 \\
\hline 15 & TYR- $\beta$ CD/CS 74 & 0 & +1 & -1 & 132.6 & 32.0 \\
\hline
\end{tabular}

Table 5. Significance of each factor equation model terms of the TYR- $\beta C D / C S$ system.

\begin{tabular}{ccc}
\hline \multirow{2}{*}{ Factor } & \multicolumn{2}{c}{$p$-Value } \\
\cline { 2 - 3 } & $\mathbf{R}_{\mathbf{1}}$ & $\mathbf{R}_{\mathbf{2}}$ \\
\hline Model & 0.0028 & 0.0016 \\
\hline $\mathrm{A}$ & 0.0006 & $<0.0001$ \\
\hline $\mathrm{B}$ & 0.1131 & 0.0130 \\
\hline $\mathrm{C}$ & 0.7221 & 0.0766 \\
\hline $\mathrm{AB}$ & 0.0204 & 0.2353 \\
\hline $\mathrm{AC}$ & - & 0.3950 \\
\hline $\mathrm{BC}$ & - & 0.5530 \\
\hline $\mathrm{A}^{2}$ & 0.0046 & 0.0080 \\
\hline $\mathrm{B}^{2}$ & - & 0.0100 \\
\hline $\mathrm{C}^{2}$ & 0.2881 & 0.0213 \\
\hline $\mathrm{R}^{2}$ & 0.8773 & 0.9760 \\
\hline Adjusted $\mathrm{R}^{2}$ & 0.7853 & 0.9327 \\
\hline Adeq Precision & 9.8620 & 15.2455 \\
\hline
\end{tabular}

For this system, the optimal preparation formula was found to be the $\mathrm{CP}$, giving the smallest nanoparticles and a $\zeta$-potential of $25.9 \mathrm{mV}$. This point was chosen for further experiments. 

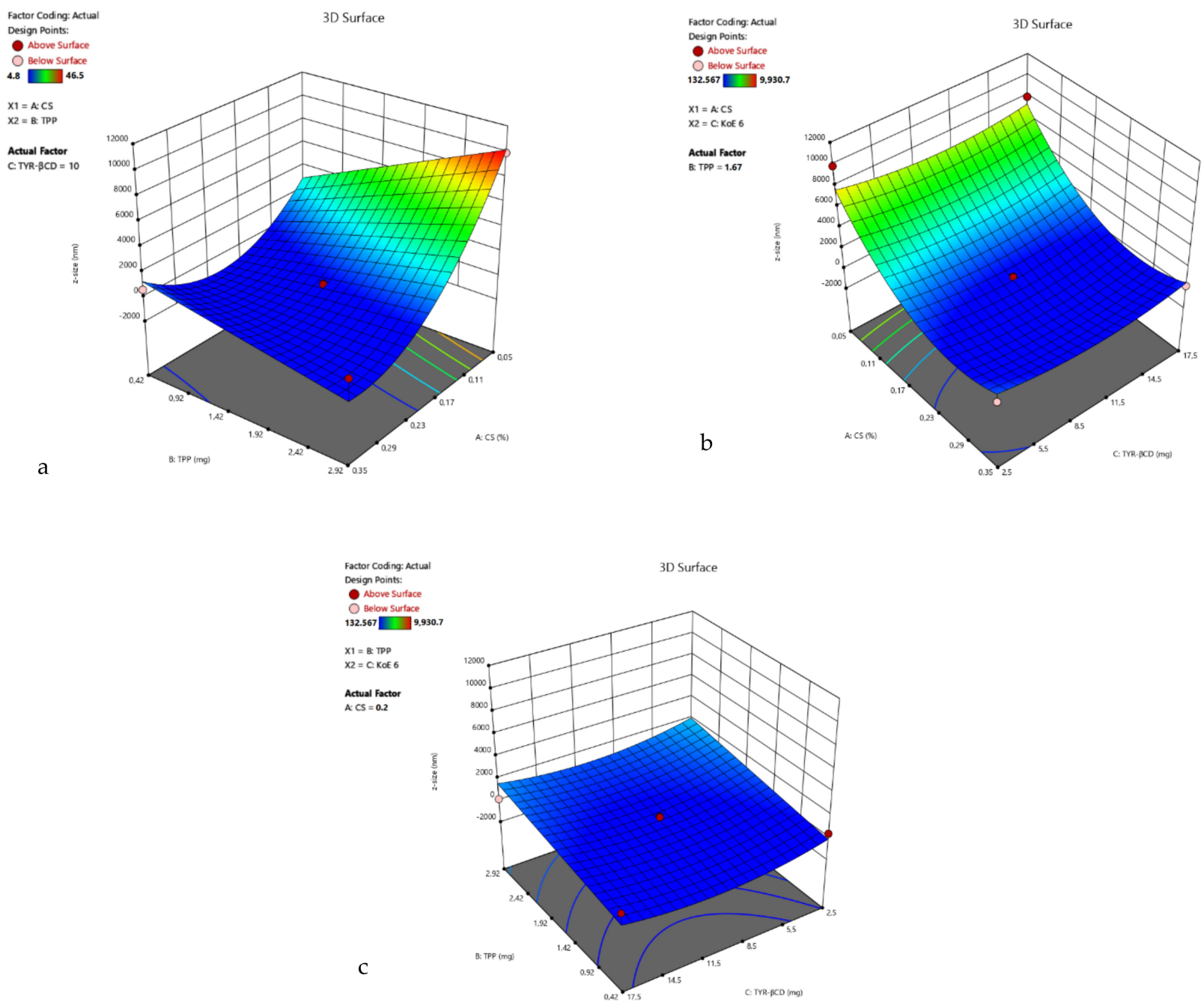

Figure 4. $3 \mathrm{D}$ surface plot of response $\mathrm{R}_{1}$ of TYR- $\beta C D / C S$ system (a) CS Vs TPP (TYR- $\beta C D: 10 \mathrm{mg}$ ) (b) CS Vs TYR- $\beta C D$ (TPP: $1.67 \mathrm{mg})$ (c) TPP Vs TYR- $\beta$ CD (CS: 0.2\%).

Comparing the experimental results, the lowest size values were given at the point $(0,+1,-1)$ and the CP. In both cases, the $\zeta$-potential was highly positive; hence, the central point was chosen for comparative reasons. This result is in accordance with the software's predictions of the optimal points.

Comparing the two nanosystems, many similarities can be observed. First, the initial concentration of chitosan in the nanoparticle-forming solution plays a significant role in the properties of the particles. Increased concentration of chitosan results in the agglomeration of particles and a very high $\zeta$-potential, attributed to the presence of many protonated amino groups. On the other hand, chitosan to TPP ratio is also important and strongly affects both responses. Moreover, the range of both responses does not differ significantly for the two systems, suggesting that the polymeric chains form a matrix entrapping the molecule or the inclusion complex and form the nanoparticles.

The main difference between the two systems is the impact of the TYR- $\beta$ CD to the $\zeta$-potential. The reason for this difference could be that the inclusion complex is negatively charged and that a strong electrostatic interaction between the oligosaccharide and chitosan exists. 


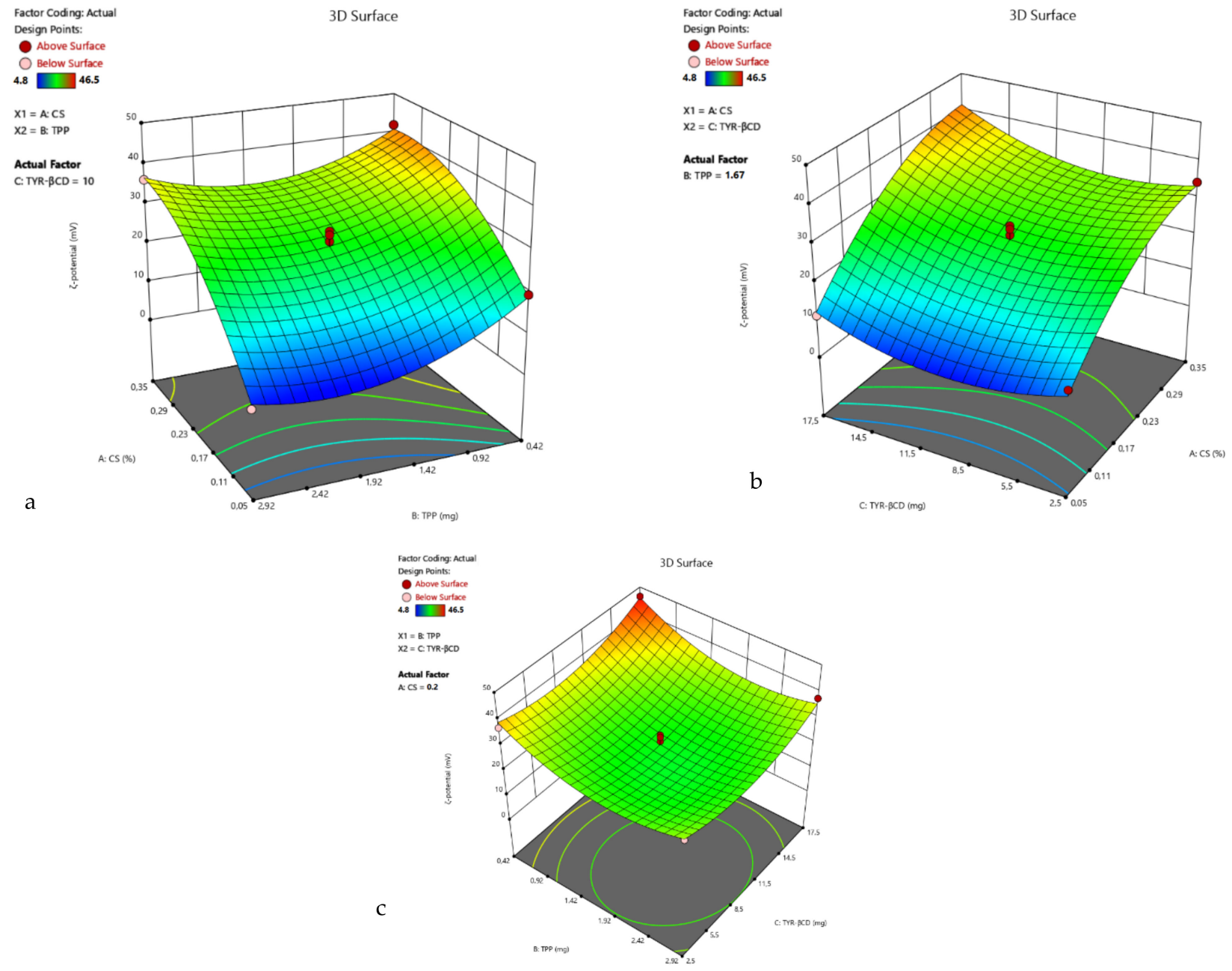

Figure 5. 3D surface plot of response $R_{2}$ of the TYR- $\beta C D / C S$ system (a) CS Vs TPP (TYR- $\beta C D: 10 \mathrm{mg}$ ) (b) CS Vs TYR- $\beta C D$ (TPP: $1.67 \mathrm{mg})(\mathbf{c})$ TPP Vs TYR- $\beta C D(C S: 0.2 \%)$.

\subsection{Encapsulation Efficiency and Loading Capacity Calculation}

After identifying the optimal conditions for obtaining nanoparticles, the encapsulation efficiency $(\mathrm{EE} \%)$ and loading capacities (LC\%) were determined for the three nanosystems.

For the inclusion complex of tyrosol with the $\beta C D$, it was found that the EE\% was $98 \%$. The high encapsulation efficiency is expected for this system, as the kneading technique was implemented, and no washing of the tyrosol was performed. The structure of $\beta C d$ is presented in Figure 6.

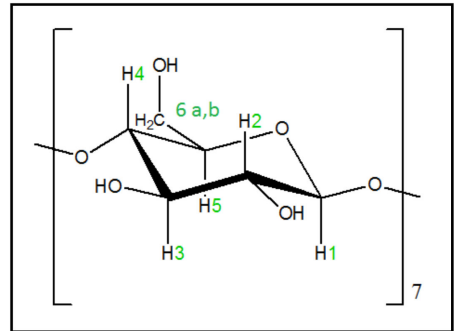

Figure 6. The glucose monomer in $\beta C D$. 
For the TYR/CS nanosystem, the EE\% was found to be $46 \%$ and the LC $12 \%$, while for the TYR- $\beta$ CD/CS nanosystem, the corresponding values were 12 and $4.2 \%$, respectively.

\subsection{Structural Identification of TYR- $\beta C D$ Using ${ }^{1} H$ NMR Spectroscopy}

The analysis of the ${ }^{1} \mathrm{H}$ NMR spectrum of the inclusion complexes with $\beta C D$ provides important evidence regarding the host-guest interactions. The ${ }^{1} \mathrm{H}$ NMR spectrum of TYR- $\beta C D$, as well as those of tyrosol and $\beta C D$, are presented in Figure 7 . In Table 6, the chemical shift changes of ${ }^{1} \mathrm{H}-\mathrm{NMR}$ signals of the protons of $\beta \mathrm{CD}$ before and after the formation of the TYR- $\beta$ CD inclusion complexes are shown.

Table 6. Chemical shift changes of ${ }^{1} \mathrm{H}-\mathrm{NMR}$ signals of $\beta C D$ before and after the formation of the TYR- $\beta$ CD IC.

\begin{tabular}{|c|c|c|c|}
\hline Proton & $\begin{array}{l}\text { Chemical Shifts }(\delta 1) \text { of } \\
\beta C D \text { Protons }(\mathrm{ppm})\end{array}$ & $\begin{array}{c}\text { Chemical Shifts }(\delta 2) \text { of } \\
\beta C D \text { Protons }(\mathrm{ppm}) \text { in } \\
\text { TYR- } \beta C D \text { IC }\end{array}$ & $\Delta \delta=(\delta 2-\delta 1) \mathrm{ppm}$ \\
\hline 1 & 5.081 & 5.077 & -0.004 \\
\hline 2 & 3.661 & 3.658 & -0.003 \\
\hline 3 & 3.975 & 3.945 & -0.030 \\
\hline 4 & 3.596 & 3.595 & -0.001 \\
\hline 5 & \multirow{2}{*}{$3.867-3.913$} & 3.813 & -0.100 \\
\hline $6 a, b$ & & 3.874 & -0.039 \\
\hline
\end{tabular}

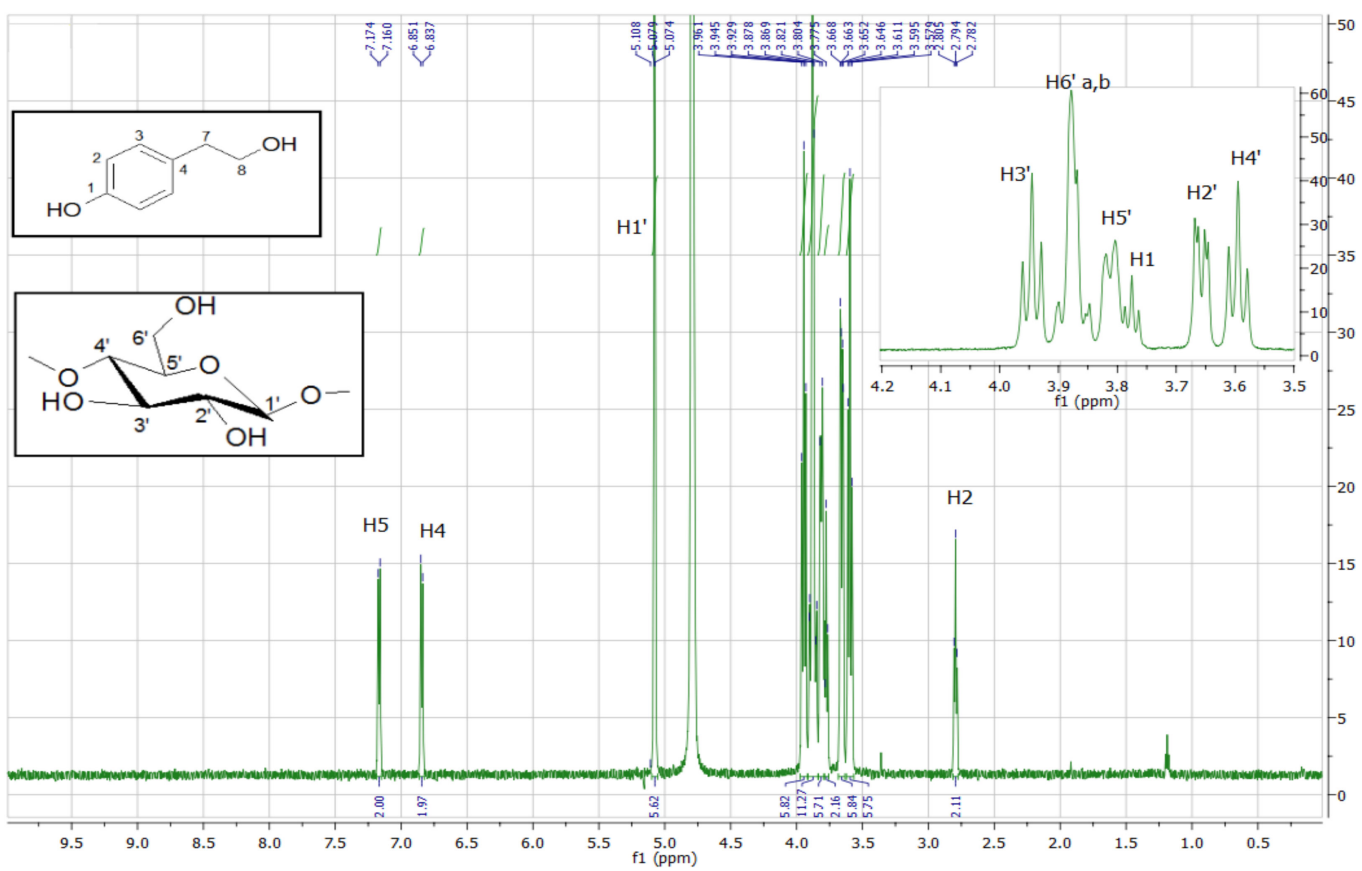

(a)

Figure 7. Cont. 


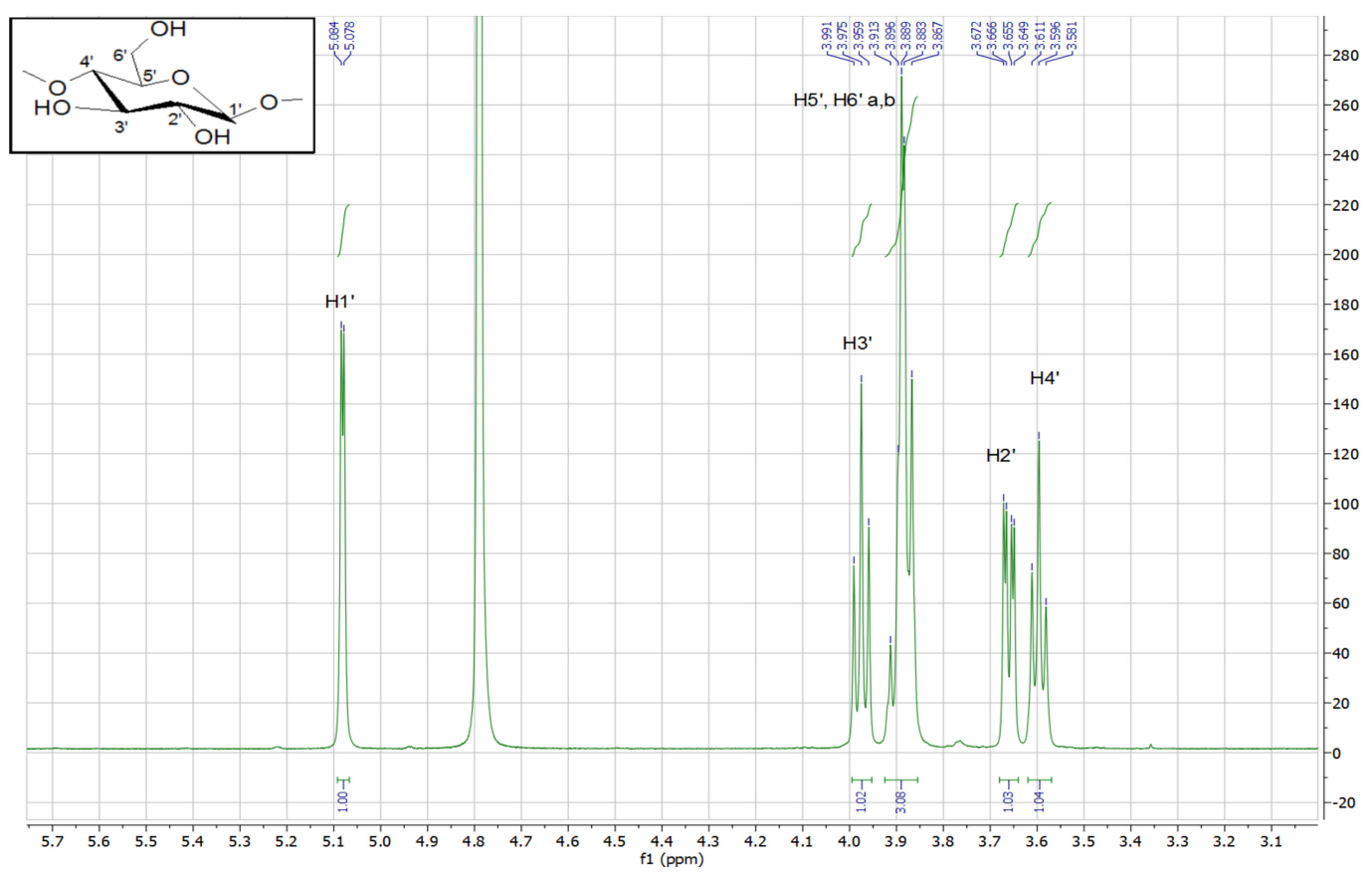

(b)

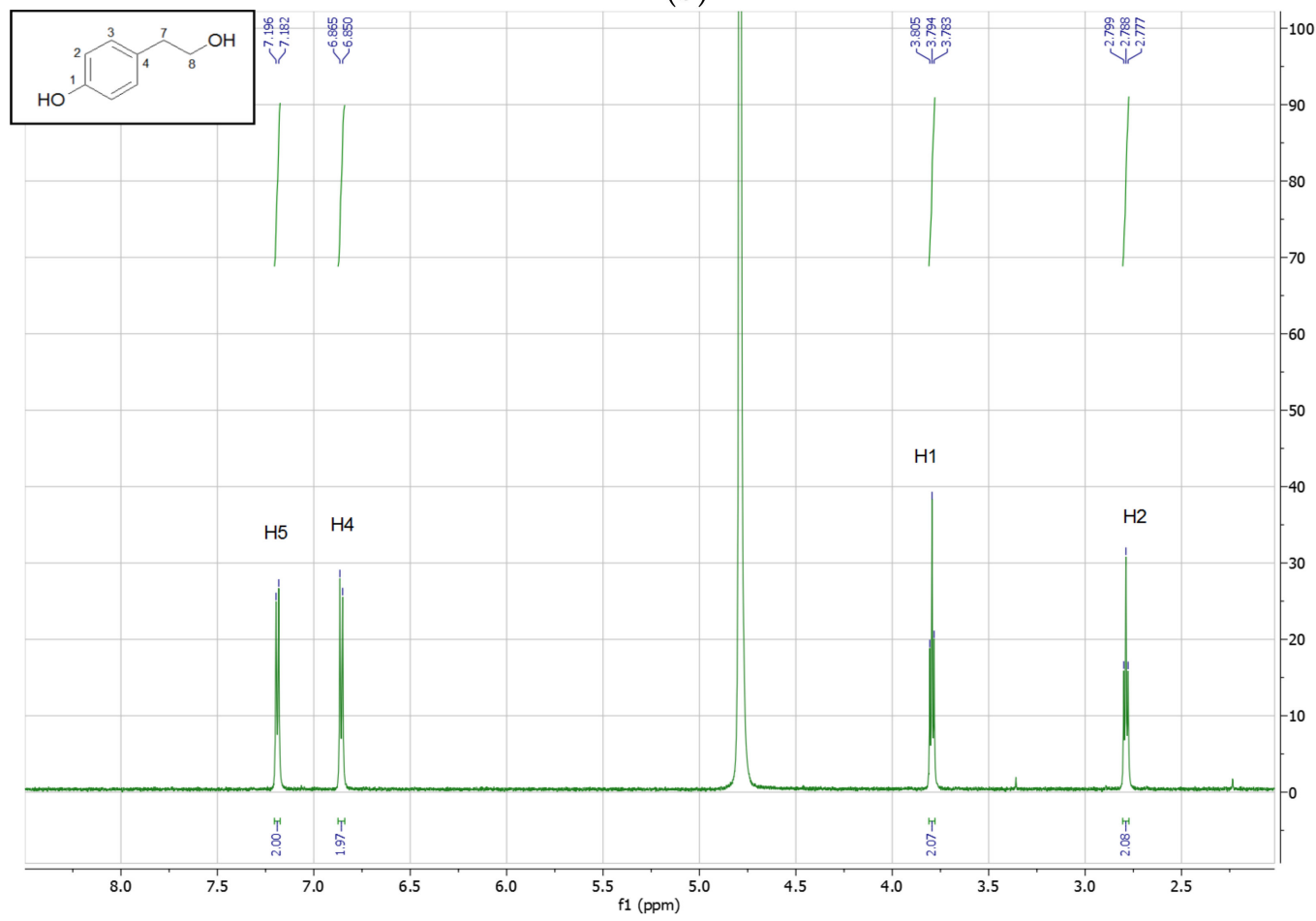

(c)

Figure 7. ${ }^{1} \mathrm{H}$ NMR spectrum $\left(600 \mathrm{MHz}, \mathrm{D}_{2} \mathrm{O}\right)$ of (a) TYR- $\beta \mathrm{CD}$ and expansion of the region 3.4-4.1 ppm, (b) $\beta C D$, and (c) tyrosol.

The peaks of the H-3 and H-5 protons of $\beta C D$ (which are located inside the cavity) present significant upfield shift ( -0.030 and $-0.100 \mathrm{ppm}$, respectively), indicative of strong hydrophobic interactions between tyrosol and $\beta C D$ inside the cavity. The upfield shift of the H-6 ( $-0.039 \mathrm{ppm})$, which lie at the primary face of the cyclodextrin cone, implies that there is also a strong interaction with tyrosol, probably between the aliphatic $\mathrm{OH}$ of the tyrosol molecule and the 6-OH of $\beta C D$. These results lead us to believe that the tyrosol molecule enters the cyclodextrin cone in such a way that the aromatic ring lies well inside the hydrophobic cavity whereas the aliphatic hydroxyethyl moiety points towards the primary face of the cone and strong hydrogen bonds are formed between the $\mathrm{OH}$ 
groups. These observations are in accordance with the results of Rescifina et al. [35] and Lopez-Garcia et al. [36], who studied the structure of the inclusion complexes of tyrosol and hydroxytyrosol with $\beta C D$.

\subsection{FT-IR Analysis of the TYR- $\beta-C D$ IC}

The analysis of the FT-IR spectra of pure $\beta C D$, tyrosol and the inclusion complex can serve as further proof of the formation of the inclusion complex. The most characteristic peaks in the FT-IR spectra of the above-mentioned compounds are shown in Table 7 and the spectra in Figure 8.

Table 7. Characteristic FT-IR absorption bands of $\beta-\mathrm{CD}$, tyrosol and the tyrosol- $\beta-\mathrm{CD}$ inclusion complex.

\begin{tabular}{cccc}
\hline & \multicolumn{3}{c}{ Characteristic Absorption Bands (cm ${ }^{-1}$ ) } \\
\hline & $\beta C D$ & Tyrosol & Inclusion Complex \\
\hline OH stretching & 3382 & 3389 & 3376 \\
\hline C-H stretching (aromatic compounds) & - & 3148 & - \\
\hline C-H stretching & 2925 & - & 2924 \\
\hline C-H asymmetric stretching $\left(\mathrm{CH}_{2}\right)$ & 1643 & - & 1643 \\
\hline C=C stretching (Aromatic compounds) & - & 1512 & 1541 \\
\hline O-H bending (alcohol) & 1415 & 1452 & 1423 \\
\hline C-O stretching (secondary alcohols) & 1029 & - & 1029 \\
\hline C-H stretching (aromatic, para substituted) & - & 818 & - \\
\hline
\end{tabular}

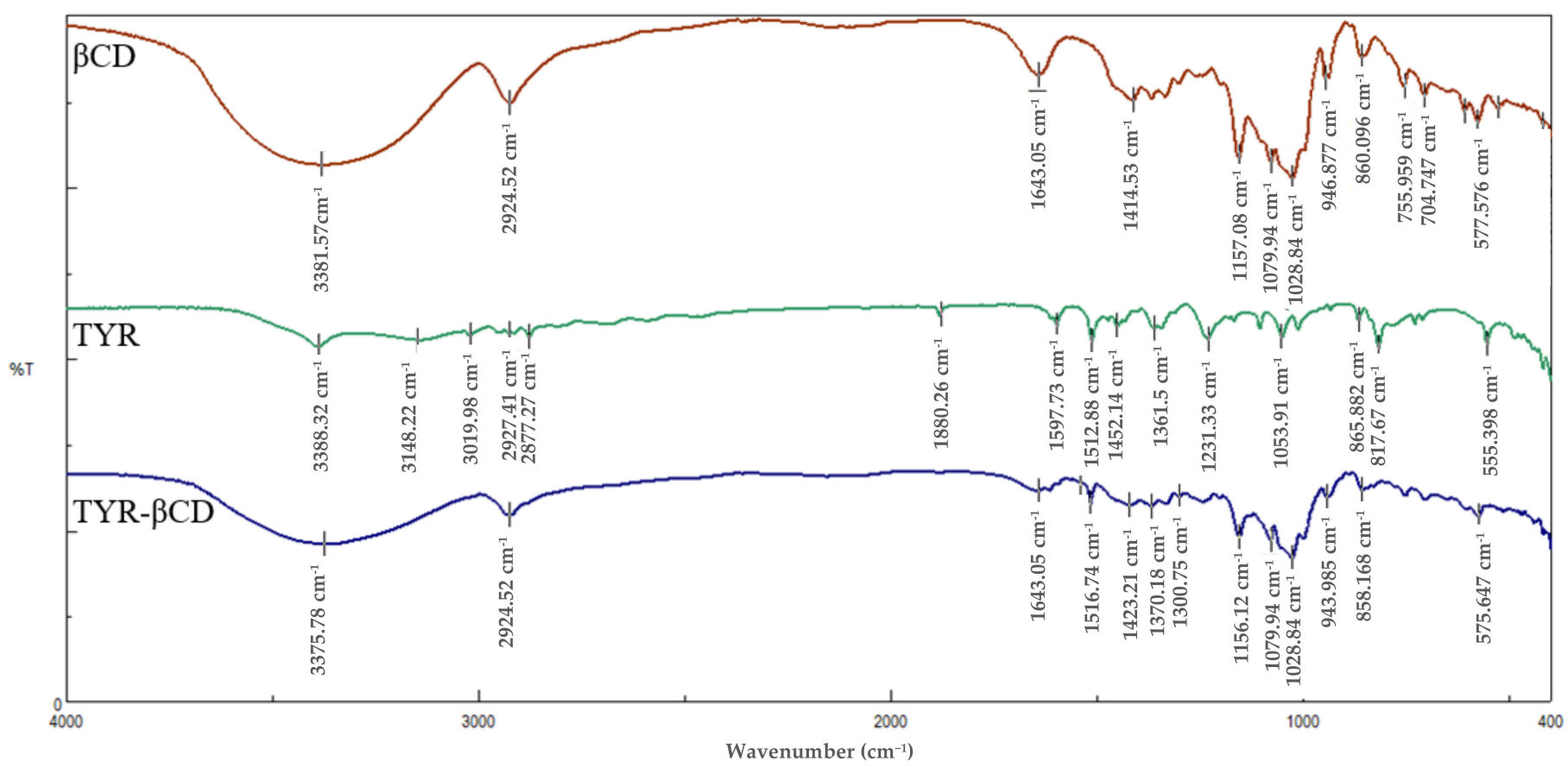

Figure 8. FT-IR spectra of $\beta-C D$ (red), tyrosol (green) and tyrosol- $\beta-C D$ inclusion complex (blue).

The FT-IR spectrum of the inclusion complex of tyrosol with $\beta C D$ (TYR- $\beta C D$ ) shows a broad absorption band at $3376 \mathrm{~cm}^{-1}$ owed to the $\mathrm{OH}$ stretching vibration. This band is shifted compared to the corresponding band at the spectra of pure $\beta C D\left(3382 \mathrm{~cm}^{-1}\right)$ and tyrosol $\left(3389 \mathrm{~cm}^{-1}\right)$. This shift is indicative of strong interactive forces between the host and guest in the inclusion complex. The band at $1543 \mathrm{~cm}^{-1}$ present in the FT-IR spectrum of 
the inclusion complex is attributed to the $\mathrm{C}=\mathrm{C}$ stretching vibration in aromatic compounds and is shifted by $29 \mathrm{~cm}^{-1}$ from the value of the same band at the spectrum of pure tyrosol. This large shift is further evidence of the efficient inclusion of tyrosol in the cyclodextrin cone with the aromatic part of the molecule lying inside the cone, as concluded also by the NMR spectra. The absorption band of the $\mathrm{OH}$ bending vibration appears at $1423 \mathrm{~cm}^{-1}$ in the spectrum of the inclusion complex and is shifted from the value of the same absorbance at the spectra of $\beta-C D$ and tyrosol by $9 \mathrm{~cm}^{-1}$ and $29 \mathrm{~cm}^{-1}$, respectively. Again, these shifts corroborate the strong interaction between tyrosol and $\beta-C D$.

\subsection{Differential Scanning Calorimetry Analysis (DSC)}

The DSC thermograms of tyrosol, the two carbohydrate carriers and the corresponding nanosystems are presented in Figure 9.

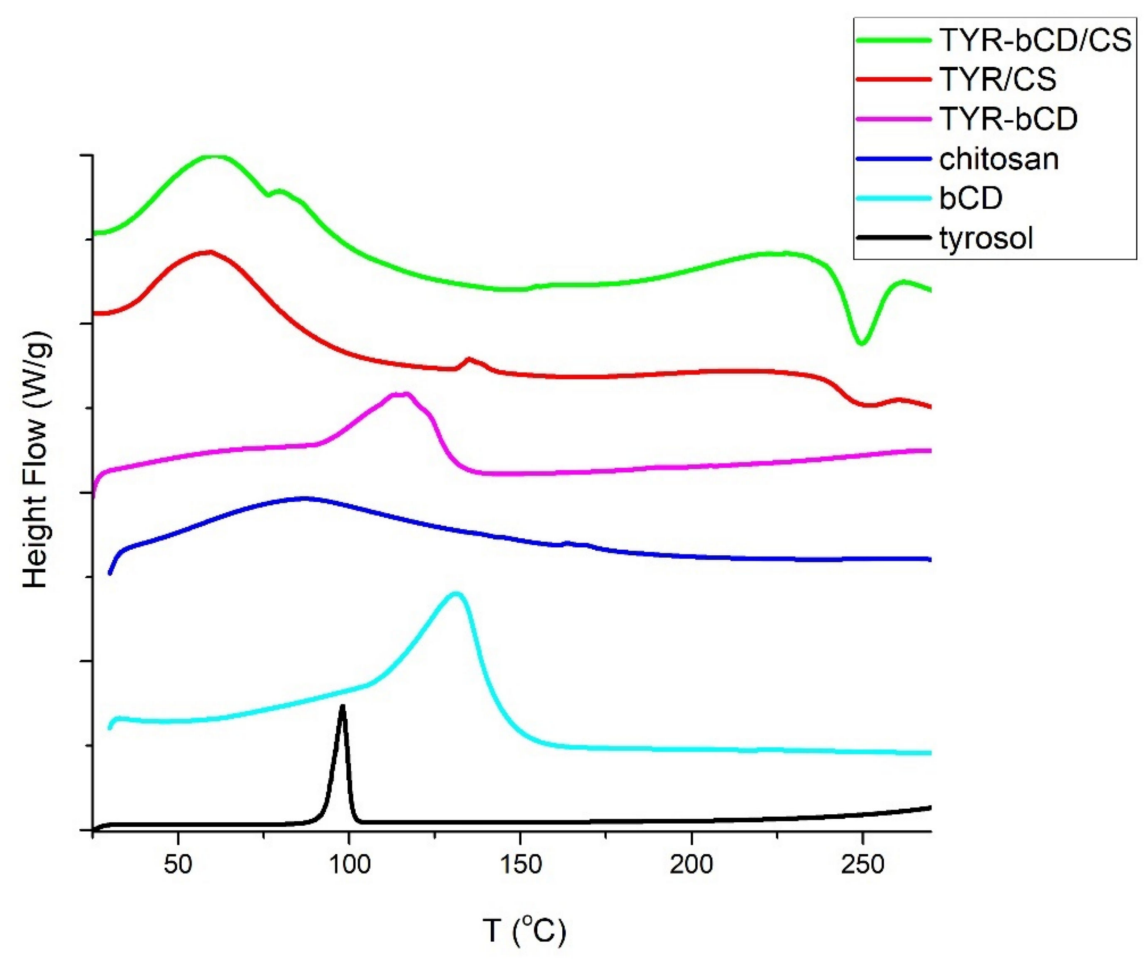

Figure 9. DSC thermograms of tyrosol (black), $\beta$-cyclodextrin (cyan), chitosan (blue), TYR- $\beta C D$ inclusion complex (magenta), TYR/CS (red), TYR- $\beta C D / C S$ (green).

In the DSC thermogram of tyrosol, the sharp endothermic process at $85-113{ }^{\circ} \mathrm{C}$ with peak at $95^{\circ} \mathrm{C}$, corresponds to the melting point of the compound [6]. In the chitosan DSC thermogram, in the studied range, only the loss of water is observed at the temperature range $85-107^{\circ} \mathrm{C}$, with a peak at $94{ }^{\circ} \mathrm{C}$ corresponding to the loss of water. The loss of water from cyclodextrin occurs in the range $98-155{ }^{\circ} \mathrm{C}$ with an endothermic peak at $131{ }^{\circ} \mathrm{C}$ [37-39].

The DSC thermogram of the inclusion complex undergoes an endothermic thermal transition from 87 to $133^{\circ} \mathrm{C}$ with peak observed at $116^{\circ} \mathrm{C}$, ascribed to the water loss. The melting of tyrosol cannot be observed in this curve, yet the decrease of the temperature of water loss, compared to the one of the pure $\beta C D$, may be evidence of the protection that the carrier offers to the molecule. This is in accordance with what has previously been reported when encapsulating a molecule in $\beta C D[37,39]$.

In the TYR/CS nanosystem, water loss occurs at $60^{\circ} \mathrm{C}$. Similarly, in the TYR- $\beta C D / C S$ nanosystem, the water loss is observed with an endothermic peak at $61^{\circ} \mathrm{C}$. Moreover, in this system a second endothermic process takes place at the temperature range $75-87^{\circ} \mathrm{C}$ 
with peak at $79^{\circ} \mathrm{C}$ and could correspond to the loss of the water bound inside the cavity of the $\beta C D$.

The endothermic peak owed to the melting of tyrosol is not present in any of the nanosystems studied, and can be considered as further evidence of the successful encapsulation of the compound in the different matrices.

\subsection{Thermogravimetric Analysis (TGA)}

The thermal stability of the samples can be determined using TGA. As can be seen in Figure 10 , the degradation temperature $\left(\mathrm{T}_{\mathrm{d}}\right)$ of $\mathrm{TYR}$ is $220^{\circ} \mathrm{C}$.

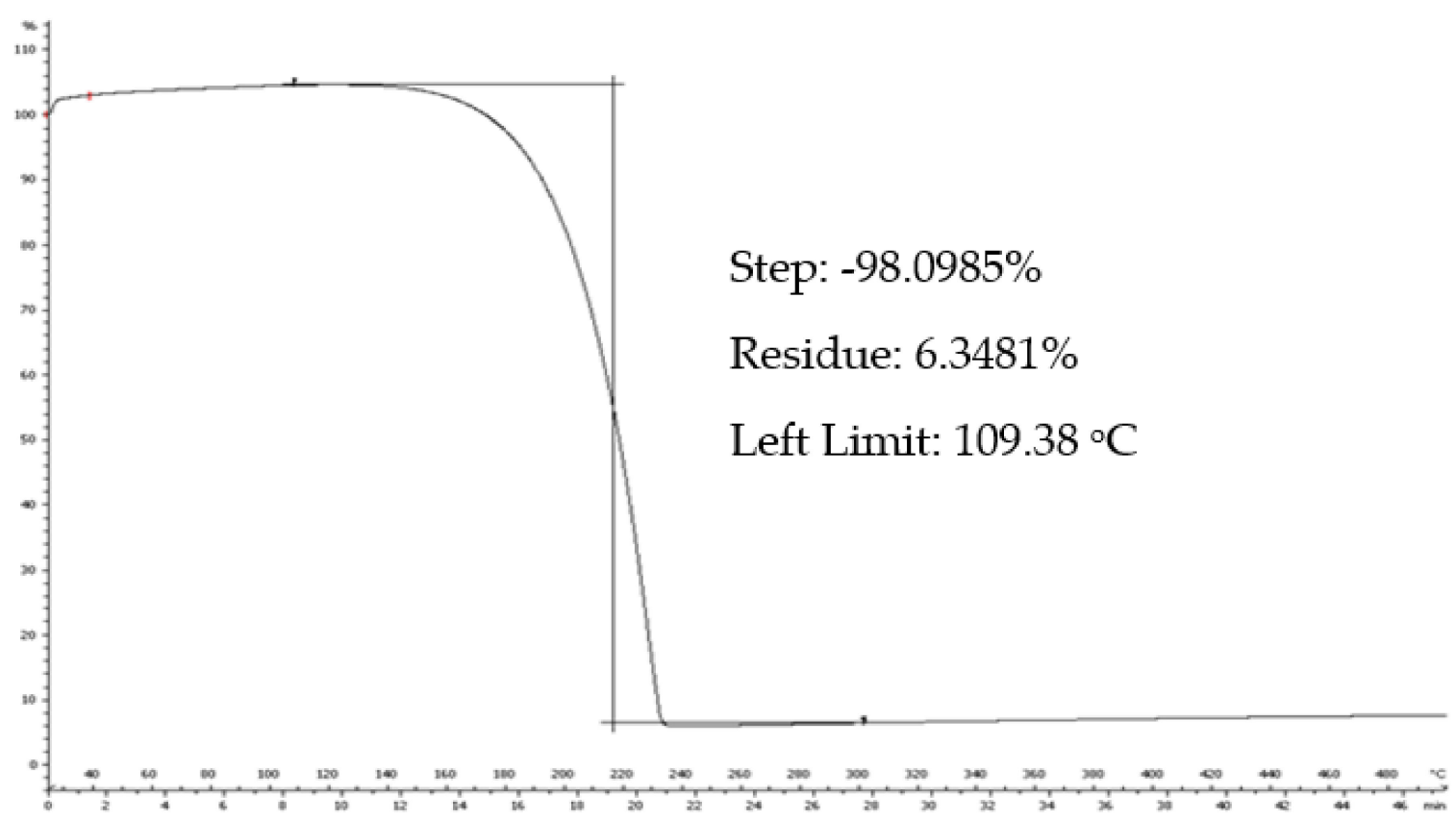

Figure 10. The TGA thermogram of tyrosol.

The thermal degradation of chitosan (Figure 11) occurs in two stages: water loss occurs at $92{ }^{\circ} \mathrm{C}$, resulting in an $8 \%$ mass loss; whereas the decomposition temperature is $300{ }^{\circ} \mathrm{C}$. The residue of the polymer at $500{ }^{\circ} \mathrm{C}$ is approximately $44 \%$.
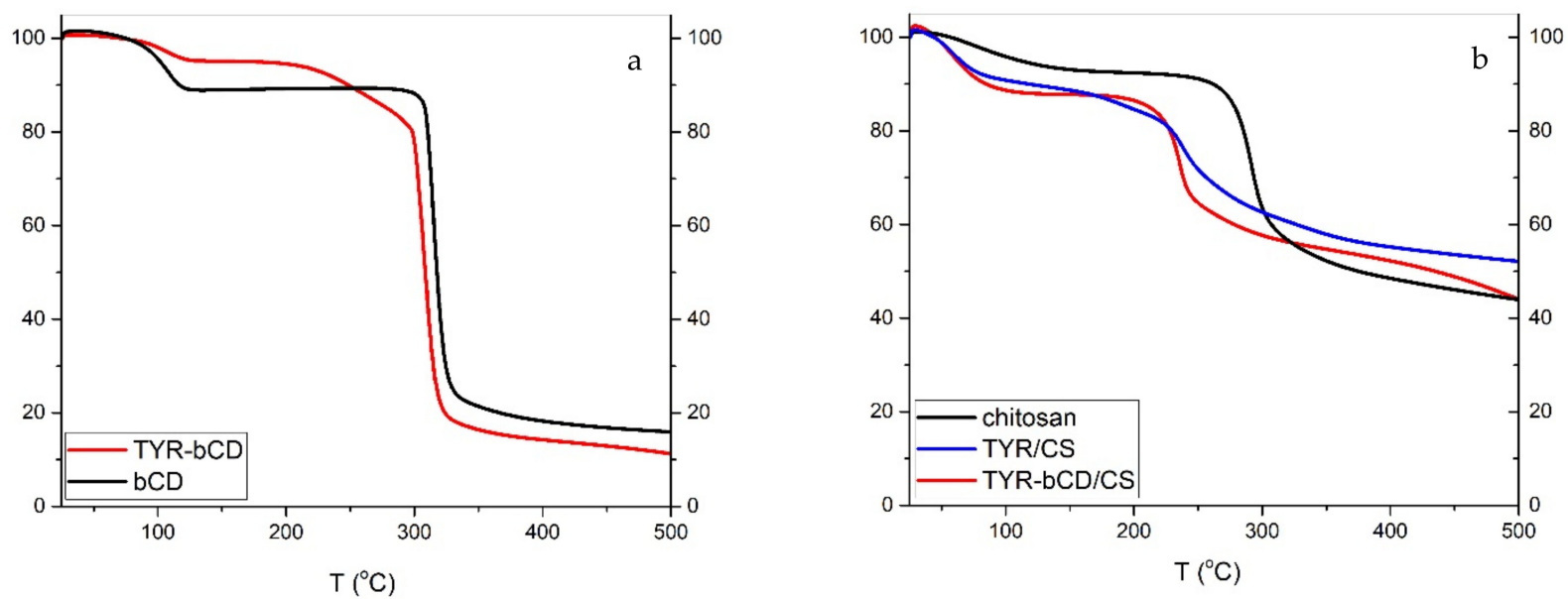

Figure 11. TGA thermograms of (a) $\beta$-cyclodextrin and TYR- $\beta C D$ and (b) chitosan, TYR/CS and TYR- $\beta C D$. 
For the TYR/CS nanosystem, the TGA profile presents three stages of degradation ((Figure 11). First, there is the water loss of at $67^{\circ} \mathrm{C}$ then there is a mass loss of $5.0 \%$ at $187^{\circ} \mathrm{C}$ that could be ascribed to tyrosol and, finally, the decomposition of chitosan occurs at $270{ }^{\circ} \mathrm{C}$, leaving a residue of $52 \%$ at $500{ }^{\circ} \mathrm{C}$. The slight decrease in the $\mathrm{T}_{\mathrm{d}}$ of chitosan is attributed to the formation of nanoparticles through anionic gelation and, hence, the synthesis of a new material [40].

In the TG curve of $\beta C D$, first there is the loss of water molecules, externally and internally bound, at $103{ }^{\circ} \mathrm{C}$, resulting in a decrease of $11 \%$ of the total mass [41]. The decomposition of $\beta C D$ happens at $323.8{ }^{\circ} \mathrm{C}$ and the mass loss is $72.4 \%$. The degradation profile of TYR- $\beta$ CD presents three stages: the water loss at $105{ }^{\circ} \mathrm{C}$ with $4.7 \%$ mass loss, then the decomposition of tyrosol at $266^{\circ} \mathrm{C}$, resulting in further mass loss of $9.5 \%$, and finally, at $316^{\circ} \mathrm{C}$, the decomposition of the $\beta C D$. The decomposition of tyrosol happens at a significantly higher temperature compared to the decomposition of the free molecule, confirming that the formation of the inclusion complex protects it from thermal degradation. The residue of the inclusion complex at $500{ }^{\circ} \mathrm{C}$ is $11 \%$.

For the double-encapsulation system TYR- $\beta$ CD/CS, TGA reveals an improved thermal stability of the system. This system degrades in two stages: at $64{ }^{\circ} \mathrm{C}$, the dehydration of the sample happens, losing approximately $14 \%$ of the mass, and at the temperature range $161-438^{\circ} \mathrm{C}$, there is another mass loss of $37 \%$, which corresponds to the degradation of the nanosystem. The residue of the sample at $500{ }^{\circ} \mathrm{C}$ is $44 \%$.

Therefore, it seems that tyrosol is better protected in the double encapsulated system than in the chitosan matrix.

\subsection{Molecular Docking}

In Figure 12, the binding architecture of tyrosol in the crystal structure of DNA (source: PDB:1bna) is presented, depicting its stabilisation in the binding cavity of minor groove of DNA. The docked complex between tyrosol and DNA is illustrated as cartoon (Figure 12a,c,d) and in the form of spheres (Figure 12b) showing the interaction of tyrosol in the binding cavity of minor groove of DNA. The minor groove is smaller in size than the major groove and has the benefit that it is available for attack from small molecules such as tyrosol. Most of the anticancer and antibiotic drugs that have been reported are small molecules, so the minor groove is important as their main binding site.

The stabilisation of the complex is achieved by the formation of hydrogen bond (Figure 12), polar and hydrophobic interactions. From the five hydrogen bonds between DC-11, DG-10, DG-14 and DG-16 nucleotides, three hydrogen bonds are formed between the aliphatic hydroxyl group of tyrosol and the purines of DG-10 and DG-16 base pairs. One more hydrogen bond is formed between the hydroxyl group and the pentose of DG-11 nucleotide and another hydrogen bond between the phenolic hydroxyl group of tyrosol and the purines of DG-14 base pair.

In addition, Table 8 illustrates the nucleotides, the number of hydrogen bonds, and the binding energy that are formed with tyrosol.

Table 8. Binding scores of the docked tyrosol on the active site of DNA.

\begin{tabular}{cccc}
\hline Ligand & $\begin{array}{c}\text { Binding Energy } \\
(\mathbf{k c a l} / \mathbf{m o l})\end{array}$ & $\begin{array}{c}\text { No. of Hydrogen } \\
\text { Bonds }\end{array}$ & Nucleotides \\
\hline DC-11, DG-10, DG-14, \\
DG-16
\end{tabular}

The above results are in accordance with the results obtained from the DNA-binding studies using UV spectroscopy, which indicated an external interaction between TYR and ctDNA. 


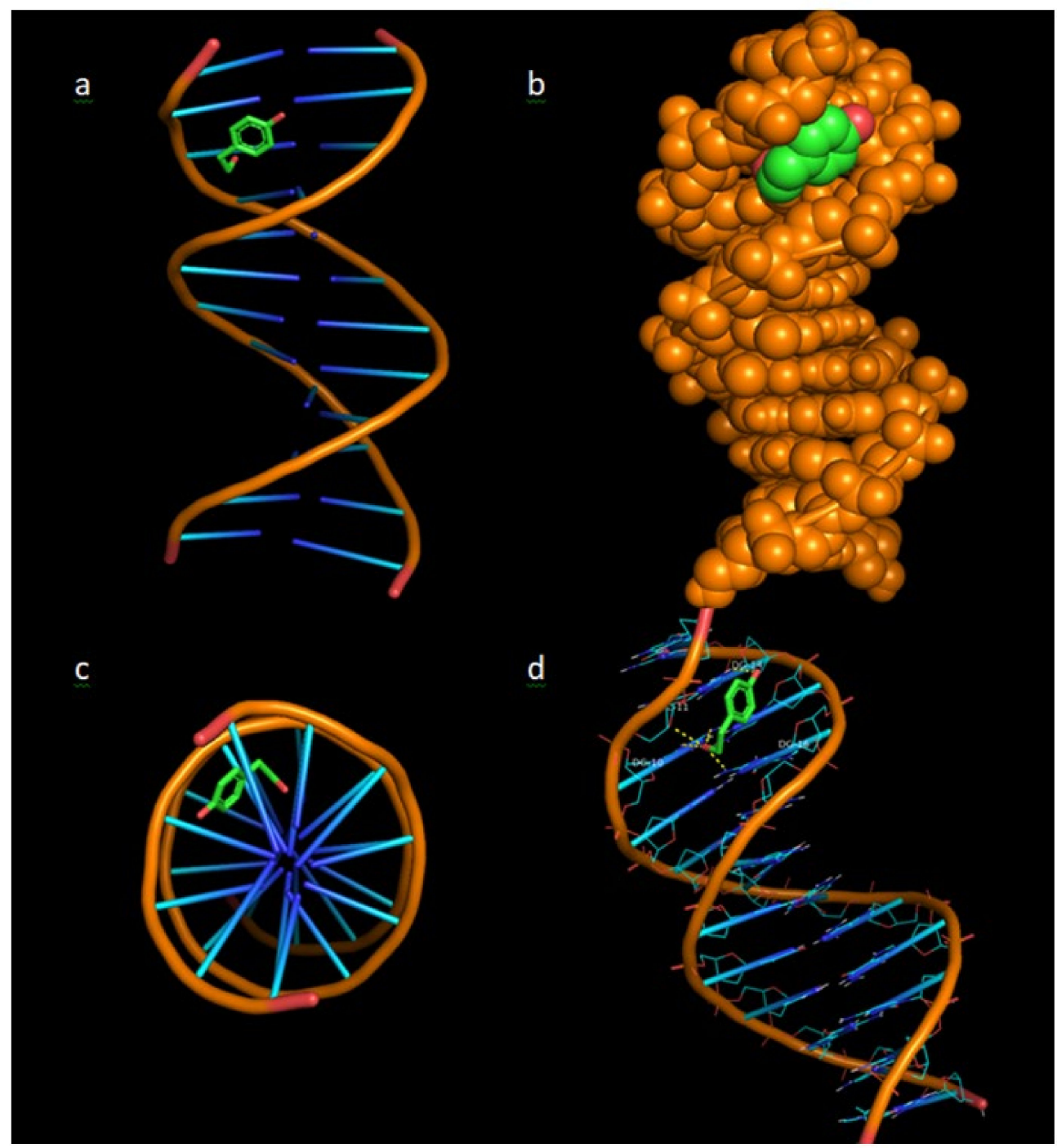

Figure 12. Binding architecture of tyrosol in the crystal structure of CT DNA (PDB:1bna) depicting its stabilisation in the binding cavity of minor groove of DNA. (a) DNA structure and tyrosol are illustrated as cartoons, (b) DNA structure and tyrosol are formed as spheres, (c) The docking pose from a view above the axis of the helix, (d) Nucleotides are rendered in line mode and the yellow dotted lines indicate hydrogen bonds between the docked molecule and the nucleotides of the binding pocket in the minor groove of DNA.

\subsection{DNA Binding Studies with ctDNA Using UV Spectroscopy}

The interaction of the compounds and nanosystems with ctDNA was studied by UV spectroscopy to obtain information on the existence of any interaction and to further calculate the DNA-binding constants of the compounds $\left(\mathrm{k}_{\mathrm{b}}\right)$. An interaction between a chemical entity and DNA can disrupt the ctDNA band located at 260-280 nm in the presence of increasing amounts of ctDNA.

In absorption spectroscopy, hyperchromism and hypochromism are significant spectral features to study the changes of the double helical structure of DNA. Due to the strong interactions between a molecule and DNA bases, a change in absorption is observed, showing the proximity of the molecule to the DNA bases. On the basis of the interaction of compounds with DNA, the binding constant $\mathrm{k}_{\mathrm{b}}$ for ligand-DNA binding was determined in the present work, using the Benesi-Hildebrand plot [42]. For the sake of comparison, the binding of a well-known xanthene dye, namely Rhodamine B, which has been shown to have a nonintercalative ctDNA binding in the DNA minor groove [43,44], was also studied. 
It is worth noting that, in the present work, no ctDNA binding was observed for any of the nanosystems at $5 \mathrm{~min}$; thus, the measurements were repeated after $30 \mathrm{~min}$. This phenomenon is attributed to the nature of the nanosystems: at $5 \mathrm{~min}$, no significant amount of tyrosol was released from the matrix of the nanosystem; whereas after $30 \mathrm{~min}$, the released tyrosol was able to bind to ctDNA. On the other hand, the binding of rhodamine B and tyrosol to ctDNA at $5 \mathrm{~min}$ and $30 \mathrm{~min}$ did not show specific change. The UV-Vis data are summarised in Table 9.

Table 9. UV-Vis absorption data for rhodamine B, tyrosol and nanosystems in the absence and presence of ctDNA.

\begin{tabular}{|c|c|c|c|c|c|c|}
\hline $\begin{array}{l}\text { Compound or } \\
\text { Nanosystem }\end{array}$ & $\begin{array}{c}\lambda_{\max } \text { Absent } \\
(\mathrm{nm})\end{array}$ & $\begin{array}{c}\lambda_{\max } \text { Present } \\
(\mathrm{nm})\end{array}$ & $\Delta \lambda(\mathrm{nm})$ & $\begin{array}{l}\text { Hypochromicity } \\
(\%)\end{array}$ & $\begin{array}{c}\text { Hyperchromicity * } \\
(\%)\end{array}$ & $\mathrm{Kb} 10^{4}\left(\mathrm{M}^{-1}\right)$ \\
\hline Rhodamine B & 554 & 554 & 0 & 26.90 & - & $10.92 \pm 0.20$ \\
\hline Tyrosol & 275.8 & 274 & 1.8 & - & 43.44 & $2.09 \pm 0.07$ \\
\hline$\beta C D$ & 261 & 259.2 & 1.8 & - & 93.43 & $0.78 \pm 0.05$ \\
\hline TYR- $\beta$ CD & 276.4 & 272.6 & 3.8 & - & 76.61 & $2.40 \pm 0.16$ \\
\hline TYR- $\beta$ CD/CS & 260.2 & 258.8 & 1.4 & - & 92.97 & $1.30 \pm 0.08$ \\
\hline
\end{tabular}

* Hyperchromicity for complexes formed by compounds and nanosystems and $100 \mu \mathrm{M}$ of ctDNA in comparison to free ligands.

As shown in Figure 13a, TYR $(100 \mu \mathrm{M}, \mathrm{pH}=7.4)$ showed absorption maxima at $275.8 \mathrm{~nm}$. With incremental addition of ctDNA to the solution of TYR, an increase in the absorption intensity at $275.8 \mathrm{~nm}$ was observed with concomitant blue shift of the $\lambda_{\max }$ at $274 \mathrm{~nm}$. This hyperchromism suggests that TYR binds to ctDNA by groove binding mode. The binding constant $(\mathrm{k})$ of TYR was calculated from the ratio of the intercept to the slope and was found to be $\mathrm{k}=2.09 \pm 0.07 \times 10^{4} \mathrm{M}^{-1}$. The results indicate the binding of TYR in the minor groove of ctDNA, as predicted by the molecular modeling studies.
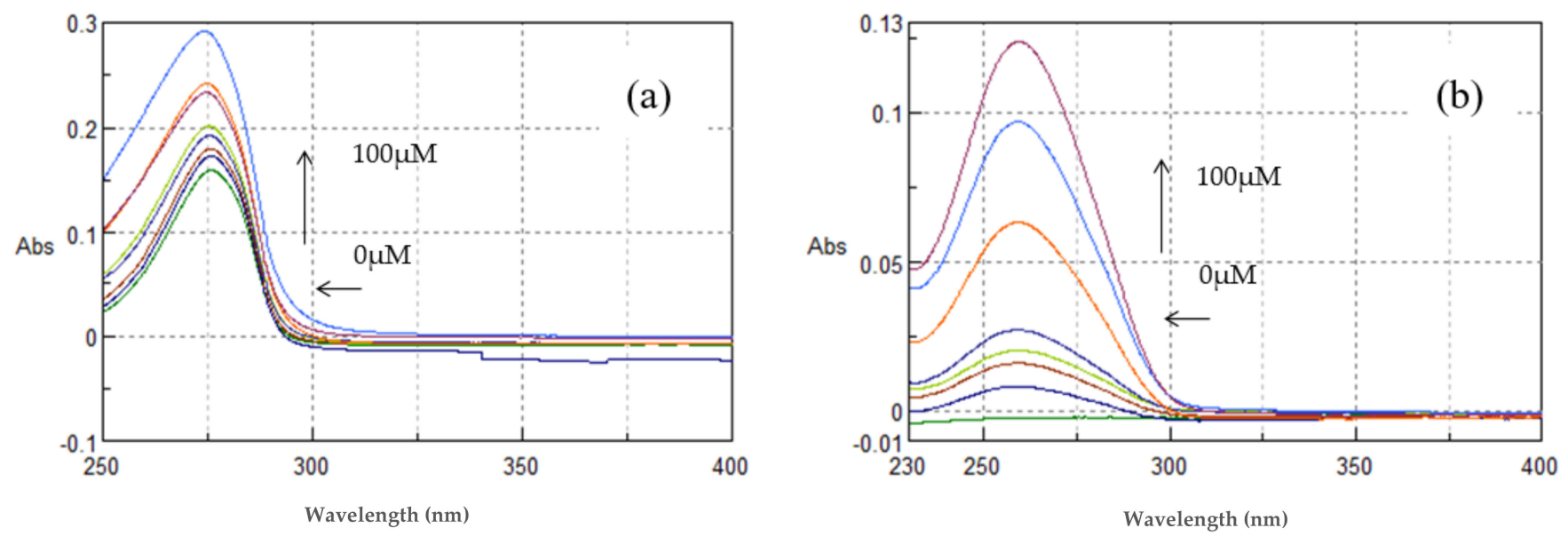

Figure 13. Absorption spectra of (a) TYR and (b) $\beta C D(100 \mu \mathrm{M}, \mathrm{pH} 7.4)$ in Tris-HCl buffer with increasing concentrations of ctDNA $(0-100 \mu \mathrm{M})$. Arrows $(\uparrow)$ and $(\leftarrow)$ refer to hyperchromic and hypochromic (blue shift) effects, respectively.

CDs are known to interact with nucleic acids. Recently, it was reported that when a complex with $\beta C D$ is formed, the deoxyribose or ribose and the phosphate groups stabilize the docked complex by hydrogen bonds with the outer rim of the CD molecules [26,45]. In this context, the interaction of $\beta-C D$ and the TYR- $\beta-C D$ inclusion complex with ctDNA was investigated.

As shown in Figure 13b, $\beta C D$ showed absorption maxima at $261 \mathrm{~nm}$. With incremental addition of ctDNA to the $\beta C D$ solution, an increase in the absorption intensity at $261 \mathrm{~nm}$ was observed with concomitant shift of the $\lambda_{\max }$ at $259.2 \mathrm{~nm}$ (blue shift). The binding 
constant $(\mathrm{k})$ of $\beta C D$ was calculated from the ratio of the intercept to the slope and was found to be $\mathrm{k}=0.78 \pm 0.05 \times 10^{4} \mathrm{M}^{-1}$. Therefore, it seems that $\beta C D$ binds to ctDNA in a non-intercalative mode, yet much less strongly than tyrosol.

As shown in Figure 14 the complex TYR- $\beta$ CD showed absorption maxima at $276.4 \mathrm{~nm}$. With incremental addition of ctDNA to the solution of TYR- $\beta C D$, an increase in the absorption intensity at $276.4 \mathrm{~nm}$ was observed with a blue shift at $\lambda_{\max } 272.6 \mathrm{~nm}$. The binding constant was found to be $\mathrm{k}=2.40 \pm 0.16 \times 10^{4} \mathrm{M}^{-1}$. The complex TYR- $\beta$ CD showed enhanced interaction with ctDNA in comparison to the free tyrosol, which could be explained by the enhanced aqueous solubility of the inclusion complex and by the mode of insertion of tyrosol in the $\beta C D$ cavity. As previously mentioned, if the aromatic ring lies well inside the hydrophobic cavity, while the aliphatic hydroxyethyl group points towards the primary face of the cone, it means that hydrogen bonds can be formed and stabilize the interaction between the complex and ctDNA.
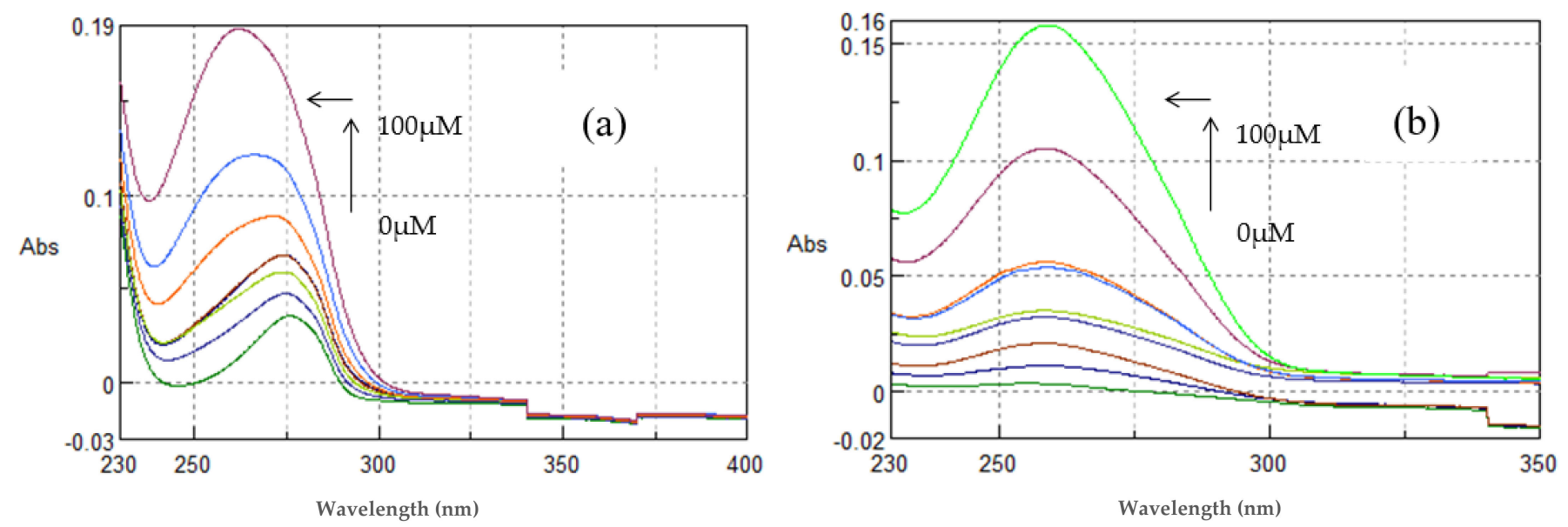

Figure 14. Absorption spectra of (a) TYR- $\beta$ CD and (b) TYR- $\beta$ CD/CS (100 $\mu \mathrm{M}, \mathrm{pH} 7.4)$ in Tris-HCl buffer with increasing concentrations of ctDNA $(0-100 \mu \mathrm{M})$. Arrows $(\uparrow)$ and $(\leftarrow)$ refer to hyperchromic and hypsochromic (blue shift) effects respectively.

The complex TYR- $\beta$ CD/CS showed absorption maxima at $260.2 \mathrm{~nm}$ (Figure 14). With incremental addition of ctDNA to the solution of TYR- $\beta C D / C S$, an increase in the absorption intensity at $260.2 \mathrm{~nm}$ was observed, with a blue shift of the $\lambda_{\max } 258.8 \mathrm{~nm}$. The binding constant was found to be $\mathrm{k}=1.30 \pm 0.08 \times 10^{4} \mathrm{M}^{-1}$.

Rhodamine $\mathrm{B}$ showed a hypochromic behaviour and the binding constant was determined to be $10.92 \pm 0.20 \times 10^{4} \mathrm{M}^{-1}$ (Figure 15). This is consistent with the minor groove binding of Rhodamine B in ctDNA, in accordance with the work of Islam et al. [44].

All the tested compounds and nanosystems, with the exception of Rhodamine B, showed hyperchromism and a blue-shift upon increasing DNA concentration, indicating that they all interact with the DNA helix. However, as no significant changes in the spectra could be observed, the results indicate a nonintercalative mode of binding. CS and TYR/CS were also studied, but no binding with ctDNA was observed. 


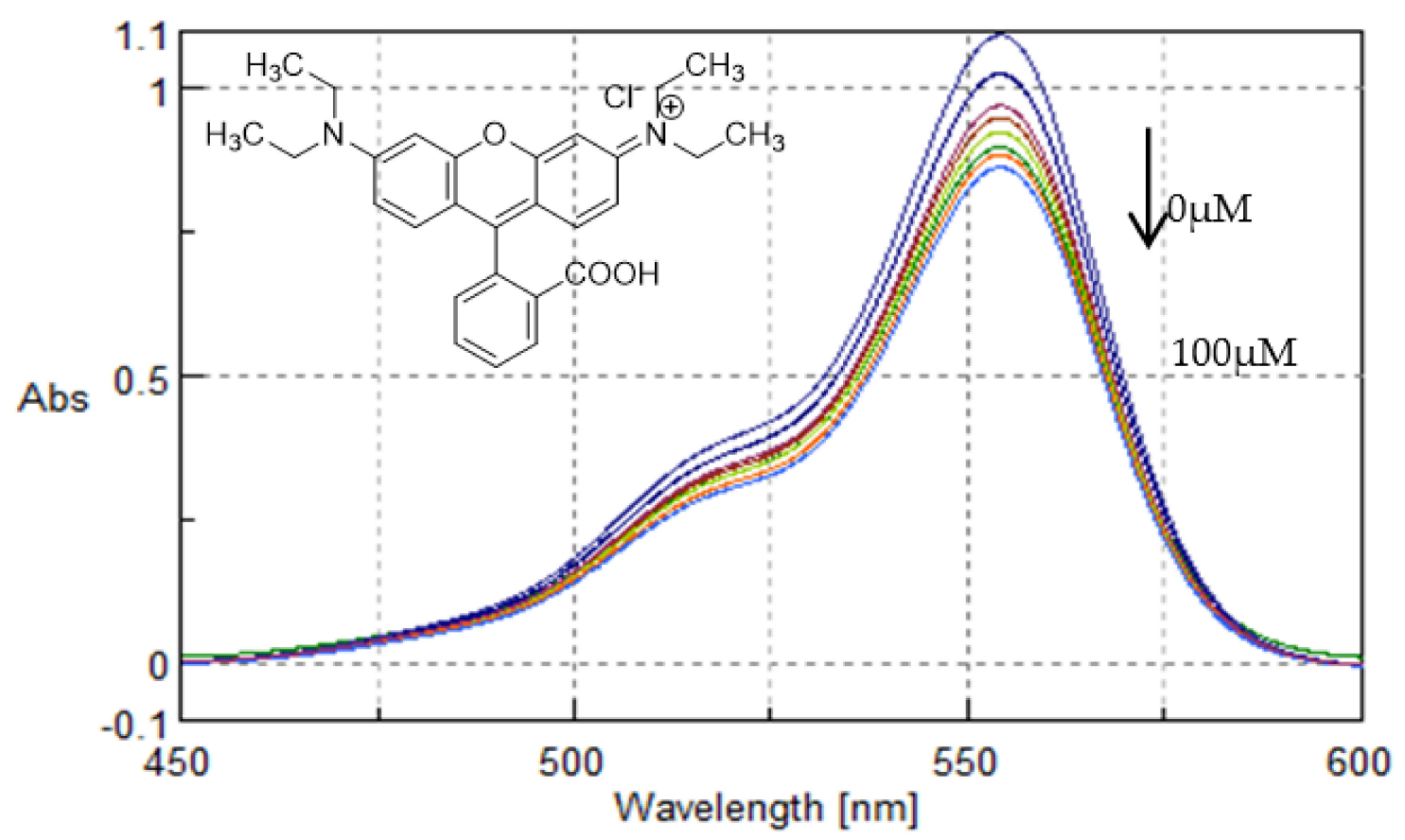

Figure 15. UV-Vis spectra of Rhodamine B with increasing concentrations of ctDNA $(0-100 \mu \mathrm{M})$. Arrow refers to hypochromic effect.

\subsection{Release Profiles}

The release profile of tyrosol was investigated for all nanosystems prepared, and the results are presented in Figure 16. For all systems, the release study was carried out for $45 \mathrm{~h}$ in a solution of $\mathrm{pH} 3.4$.

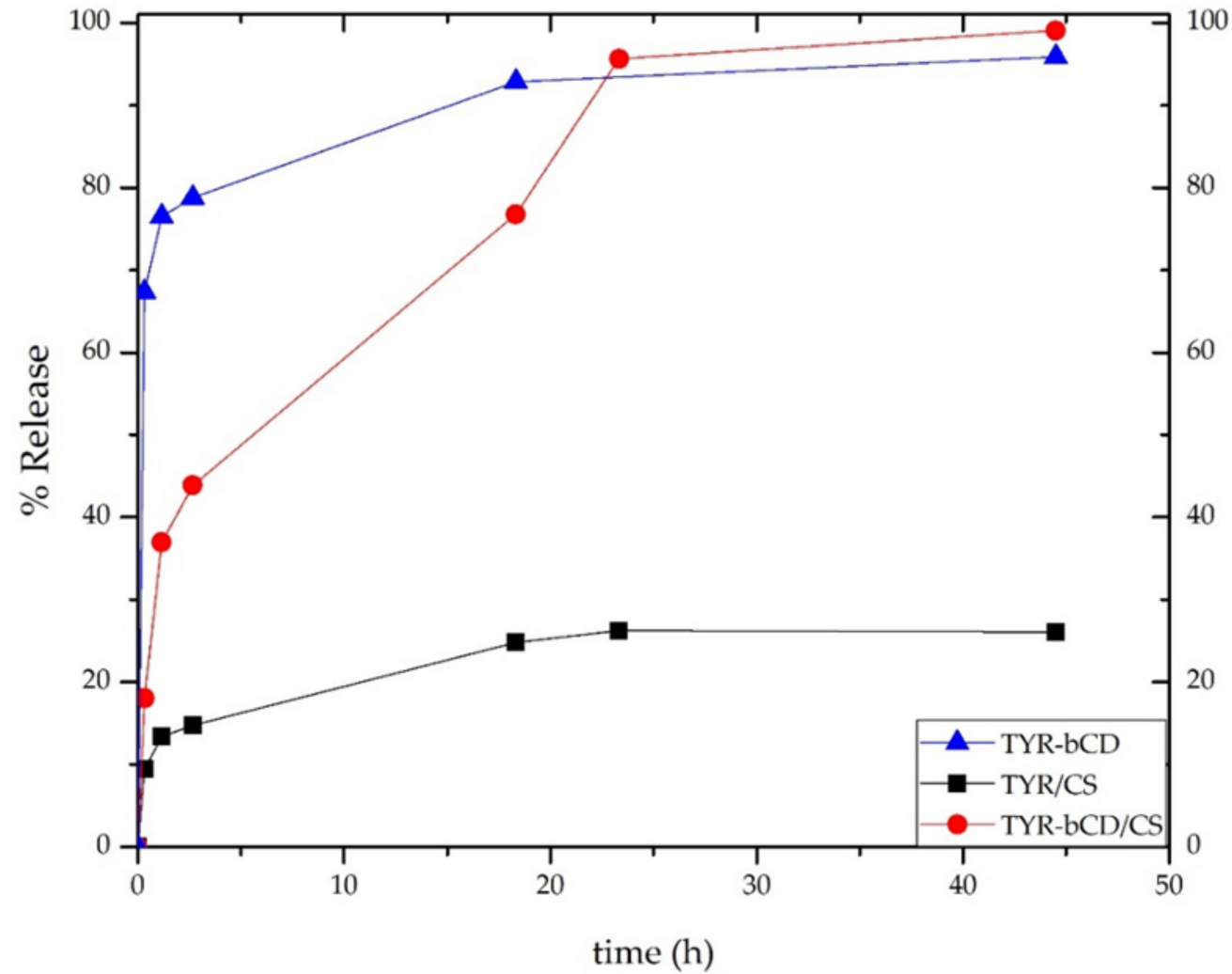

Figure 16. The release profile of tyrosol from TYR- $\beta C D$ (blue line), TYR/CS (black line) and TYR- $\beta C D / C S$ (red line). 
All nanosystems showed a "burst release" of tyrosol during the first hour. For the TYR- $\beta$ CD system, approximately $77 \%$ of the encapsulated tyrosol was released during that time. Thereafter, the release rate significantly slowed down, reaching $93 \%$ after $18 \mathrm{~h}$.

On the other hand, the release profile of tyrosol from the TYR/CS system was significantly different. During the first hour of the study, $13 \%$ of tyrosol was released reaching the maximum release after $23 \mathrm{~h}(26 \%)$.

For the TYR- $\beta$ CD/CS system, $37 \%$ of the encapsulated tyrosol was released during the first hour, reaching the $99 \%$ after $45 \mathrm{~h}$. The slower rate presented by this system as compared to the TYR- $\beta C D$ system can be attributed to the existence of chitosan as a coating and provides proof that this "double" encapsulation system can offer a more sustained release than the TYR/ $\beta C D$ by slowing down the initial burst effect observed in the case of the inclusion complex.

\section{Discussion}

The comparative study of the optimisation of the encapsulation parameters of tyrosol and the inclusion complex of $\beta$-cyclodextrin:tyrosol in chitosan revealed that the concentration of chitosan plays a significant role on the properties of the particles that are formed. Moreover, the ratio between the polymer and the cross-linking agent or the molecule to be encapsulated also affects the responses of the particulate system. In both systems studied, it was observed that the smaller sized particles presented a good $\zeta$-potential, which is indicative of a very stable formulation.

The interaction of tyrosol, the inclusion complex of tyrosol with $\beta C D$ and the inclusion complex coated with chitosan with ctDNA was studied in an effort to elucidate the potential of the prepared nanosystems to be exploited as pharmacologically active agents. Tyrosol and all the examined nanosystems showed a nonintercalative mode of binding to ctDNA. The complexation of tyrosol with cyclodextrin resulted in slightly better interaction with ctDNA as compared to the interaction exhibited by the TYR- $\beta$ CD/CS system. This difference is attributed to the small, yet existent, interaction of the oligosaccharide with ctDNA whereas the polysaccharide chitosan did not interact with ctDNA in the performed experiments. Moreover, from the NMR analysis of the inclusion complex, it was deduced that the aromatic ring of the molecule lies inside the cavity, while the aliphatic hydroxyethyl moiety points towards the primary face of the cone. Therefore, it could be suggested that $\beta C D$ carries the molecule close to ctDNA and an interaction can be observed. On the other hand, no interaction was observed when tyrosol was encapsulated in chitosan nanoparticles, presumably due to the strong positive charge on the surface of the TYR/CS nanosystem which impedes it from approaching DNA.

Finally, the release profile of tyrosol is different for each nanosystem. A burst effect is observed for all systems. The release of tyrosol from the inclusion complex formed with $\beta C D$ is completed in approximately $20 \mathrm{~h}$ hours, but when chitosan coating is added, the release rate is delayed significantly. On the other hand, when tyrosol is encapsulated into chitosan nanoparticles, the release of only the $26 \%$ of encapsulated tyrosol occurs during the same time.

\section{Conclusions}

In the present study, the impact of two different carriers for the encapsulation of tyrosol is investigated: the oligosaccharide $\beta$-cyclodextrin and the polysaccharide chitosan. The effect of coating the tyrosol- $\beta C D$ inclusion complex with chitosan was also investigated as a potential tool to modify the release profile of the bioactive compound. We were gratified to find that this was true for the systems studied in this work: the coating resulted in a sustained release of tyrosol and slowed down the initial burst effect observed from the inclusion complex.

For the formation of the tyrosol- $\beta C D$ inclusion complex a well-known methodology was implemented, whereas for the two chitosan-containing systems, the formation of the 
nanoparticles was succeeded via the ionic gelation method with sodium tripolyphosphate. The latter processes were optimised using experimental design.

Moreover, the interaction of tyrosol and the corresponding nanosystems with ctDNA was investigated. The results show that tyrosol is a ctDNA groove binder and this was confirmed by molecular modeling studies. The same mode of binding was found for the TYR/ $\beta C D$ and TYR/ $\beta C D / C S$ nanosystems.

Author Contributions: Conceptualisation, A.D. and A.R.N.P.; Methodology, A.R.N.P., E.K., M.M.B.; Software, A.R.N.P., E.K., M.M.B.; Resources, A.D.; Data Curation, A.R.N.P., E.K., M.M.B.; WritingOriginal Draft Preparation, A.D., A.R.N.P., E.K., M.M.B.; Writing-Review \& Editing, A.D., A.R.N.P., E.K., M.M.B.; Supervision, A.D.; Project Administration, A.D. All authors have read and agreed to the published version of the manuscript.

Funding: A R N Pontillo would like to thank the General Secretariat for Research and Technology (GSRT) and the Hellenic Foundation for Research and Innovation (HFRI) for funding her PhD research. M Bairaktari gratefully acknowledges financial support from State Scholarships Foundation (IKY): This research is co-financed by Greece and the European Union (European Social Fund- ESF) through the Operational Programme "Human Resources Development, Education and Lifelong Learning" in the context of the project "Strengthening Human Resources Research Potential via Doctorate Research" (MIS-5000432), implemented by the State Scholarships Foundation (IK $\Upsilon$ ).

Institutional Review Board Statement: Not applicable.

Informed Consent Statement: Not applicable.

Data Availability Statement: Data sharing not applicable.

Conflicts of Interest: The authors declare no conflict of interest.

\section{References}

1. Covas, M.I.; EMiro-Casas, M.; Fito, M.; Farre-Albadalejo, E.; Gimeno, J.; Marrugat, J.; De La Torre, R. Bioavailability of tyrosol, an antioxidant phenolic compound present in wine and olive oil, in humans. Drugs Exp. Clin. Res. 2003, 29, 203. [PubMed]

2. Di Benedetto, R.; Varì, R.; Scazzocchio, B.; Filesi, C.; Santangelo, C.; Giovannini, C.; Matarrese, P.; D’Archivio, M.; Masella, R. Tyrosol, the major extra virgin olive oil compound, restored intracellular antioxidant defences in spite of its weak antioxidative effectiveness. Nutr. Metab. Cardiovasc. Dis. 2007, 17, 535-545. [CrossRef] [PubMed]

3. San Miguel-Chávez, R. Phenolic antioxidant capacity: A review of the state of the art. Phenolic Compd. Biol. Act. 2017, 59-74. [CrossRef]

4. St-Laurent-Thibault, C.; Arseneault, M.; Longpre, F.; Ramassamy, C. Tyrosol and hydroxytyrosol two main components of olive oil, protect N2a cells against amyloid- $\beta$-induced toxicity involvement of the NF-кB signaling. Curr. Alzheimer Res. 2011, 8 , 543-551. [CrossRef]

5. Gris, E.F.; Mattivi, F.; Ferreira, E.A.; Vrhovsek, U.; Filho, D.W.; Pedrosa, R.C.; Bordignon-Luiz, M.T. Stilbenes and tyrosol as target compounds in the assessment of antioxidant and hypolipidemic activity of Vitis vinifera red wines from Southern Brazil. J. Agric. Food Chem. 2011, 59, 7954-7961. [CrossRef]

6. Paulo, F.; Santos, L. Encapsulation of the Antioxidant Tyrosol and Characterization of Loaded Microparticles: An Integrative Approach on the Study of the Polymer-Carriers and Loading Contents. Food Bioproc. Tech. 2020, 1-22. [CrossRef]

7. Suganya, V.; Anuradha, V. Microencapsulation and nanoencapsulation: A review. Int. J. Pharm. Clin. Res. 2017, 9, 233-239. [CrossRef]

8. Shahidi, F.; Han, X.Q. Encapsulation of food ingredients. Crit. Rev. Food Sci. Nutr. 1993, 33, 501-547. [CrossRef]

9. Singh, R.; Lillard, J.W., Jr. Nanoparticle-based targeted drug delivery. Exp. Mol. Pathol. 2009, 86, 215-223. [CrossRef]

10. Kedare, S.B.; Singh, R.P. Genesis and development of DPPH method of antioxidant assay. Int. J. Food Sci. Technol. 2011, 48, 412-422. [CrossRef]

11. Del Valle, E.M. Cyclodextrins and their uses: A review. Process. Biochem. 2004, 39, 1033-1046. [CrossRef]

12. Tiwari, G.; Tiwari, R.; Rai, A.K. Cyclodextrins in delivery systems: Applications. J. Pharm. Bioallied. Sci. 2010, 2, 72. [CrossRef] [PubMed]

13. Villalonga, R.; Cao, R.; Fragoso, A. Supramolecular chemistry of cyclodextrins in enzyme technology. Chem. Rev. 2007, 107, 3088-3116. [CrossRef] [PubMed]

14. Ramos, M.A.D.S.; Da Silva, P.B.; Spósito, L.; De Toledo, L.G.; Bonifacio, B.V.; Rodero, C.F.; Dos Santos, K.C.; Chorilli MBauab, T.M. Nanotechnology-based drug delivery systems for control of microbial biofilms: A review. Int. J. Nanomed. 2018, 13, 1179. [CrossRef]

15. Bellich, B.; D'Agostino, I.; Semeraro, S.; Gamini, A.; Cesàro, A. The good, the bad and the ugly of chitosans. Mar. Drugs 2016, 14, 99. [CrossRef] 
16. Muxika, A.; Etxabide, A.; Uranga, J.; Guerrero, P.; De La Caba, K. Chitosan as a bioactive polymer: Processing, properties and applications. Int. J. Biol. Macromol. 2017, 105, 1358-1368. [CrossRef]

17. Pontillo, A.R.N.; Detsi, A. Nanoparticles for ocular drug delivery: Modified and non-modified chitosan as a promising biocompatible carrier. Nanomedicine 2019, 14, 1889-1909. [CrossRef]

18. Cheung, R.C.F.; Ng, T.B.; Wong, J.H.; Chan, W.Y. Chitosan: An update on potential biomedical and pharmaceutical applications. Mar. Drugs 2015, 13, 5156-5186. [CrossRef]

19. Detsi, A.; Kavetsou, E.; Kostopoulou, I.; Pitterou, I.; Pontillo, A.R.N.; Tzani, A.; PChristodoulou ASiliachli Zoumpoulakis, P. Nanosystems for the encapsulation of natural products: The case of chitosan biopolymer as a matrix. Pharmaceutics 2020, 12, 669. [CrossRef]

20. Koukouzelis, D.; Pontillo, A.R.N.; Koutsoukos, S.; Pavlatou, E.; Detsi, A. Ionic liquid-Assisted synthesis of silver mesoparticles as efficient surface enhanced Raman scattering substrates. J. Mol. Liq. 2020, 306, 112929. [CrossRef]

21. Koutsoukos, S.; Tsiaka, T.; Tzani, A.; Zoumpoulakis, P.; Detsi, A. Choline chloride and tartaric acid, a Natural Deep Eutectic Solvent for the efficient extraction of phenolic and carotenoid compounds. J. Clean. Prod. 2019, 241, 118384. [CrossRef]

22. Tsintavi, E.; Rekkas, D.M.; Bettini, R. Partial tablet coating by 3D printing. Int. J. Pharm. 2020, 581, 119298. [CrossRef] [PubMed]

23. Zhao, J.; Li, W.; Ma, R.; Chen, S.; Ren, S.; Jiang, T. Design, synthesis and DNA interaction study of new potential DNA bis-intercalators based on glucuronic acid. Int. J. Mol. Sci. 2013, 14, 16851-16865. [CrossRef] [PubMed]

24. Pasolli, M.; Dafnopoulos, K.; Andreou, N.P.; Gritzapis, P.S.; Koffa, M.; Koumbis, A.E.; Psomas, G.; Fylaktakidou, K.C. Pyridine and p-nitrophenyl oxime esters with possible photochemotherapeutic activity: Synthesis, DNA photocleavage and DNA binding studies. Molecules 2016, 21, 864. [CrossRef]

25. Alves, P.S.; Mesquita, O.N.; Rocha, M.S. Controlling Cooperativity in $\beta$-Cyclodextrin-DNA Binding Reactions. J. Phys. Chem. Lett. 2015, 6, 3549-3554. [CrossRef]

26. Leclercq, L. Interactions between cyclodextrins and cellular components: Towards greener medical applications? Beilstein J. Org. Chem. 2016, 12, 2644-2662. [CrossRef]

27. García-Padial, M.; Martínez-Ohárriz, M.C.; Isasi, J.R.; Vélaz, I.; Zornoza, A. Complexation of tyrosol with cyclodextrins. J. Incl. Phenom. Macrocycl. Chem. 2013, 75, 241-246. [CrossRef]

28. Tang, B.; Shen, F.; Wan, D.; Guo, B.H.; Wang, Y.J.; Yi, Q.Y.; Liu, Y.J. DNA-binding, molecular docking studies and biological activity studies of ruthenium (II) polypyridyl complexes. RSC Adv. 2017, 7, 34945-34958. [CrossRef]

29. Singla, P.; Luxami, V.; Paul, K. Quinazolinone-benzimidazole conjugates: Synthesis, characterization, dihydrofolate reductase inhibition, DNA and protein binding properties. J. Photochem. Photobiol. B Biol. 2017, 168, 156-164. [CrossRef]

30. Delan, W.K.; Zakaria, M.; Elsaadany, B.; ElMeshad, A.N.; Mamdouh, W.; Fares, A.R. Formulation of simvastatin chitosan nanoparticles for controlled delivery in bone regeneration: Optimization using Box-Behnken design, stability and in vivo study. Int. J. Pharm. 2020, 577, 119038. [CrossRef]

31. Shah, B.; Khunt, D.; Misra, M.; Padh, H. Application of Box-Behnken design for optimization and development of quetiapine fumarate loaded chitosan nanoparticles for brain delivery via intranasal route*. Int. J. Biol. Macromol. 2016, 89, 206-218. [CrossRef] [PubMed]

32. Kalam, M.A.; Khan, A.A.; Khan, S.; Almalik, A.; Alshamsan, A. Optimizing indomethacin-loaded chitosan nanoparticle size, encapsulation, and release using Box-Behnken experimental design. Int. J. Biol. Macromol. 2016, 87, 329-340. [CrossRef] [PubMed]

33. Yan, J.; Guan, Z.Y.; Zhu, W.F.; Zhong, L.Y.; Qiu, Z.Q.; Yue, P.F.; Wu, W.T.; Liu, J.; Huang, X. Preparation of Puerarin Chitosan Oral Nanoparticles by Ionic Gelation Method and Its Related Kinetics. Pharmaceutics 2020, 12, 216. [CrossRef] [PubMed]

34. Sharma, M.; Sharma, R.; Jain, D.K.; Saraf, A. Enhancement of oral bioavailability of poorly water soluble carvedilol by chitosan nanoparticles: Optimization and pharmacokinetic study. Int. J. Biol. Macromol. 2019, 135, 246-260. [CrossRef] [PubMed]

35. Rescifina, A.; Chiacchio, U.; Iannazzo, D.; Piperno, A.; Romeo, G. $\beta$-cyclodextrin and caffeine complexes with natural polyphenols from olive and olive oils: NMR, thermodynamic, and molecular modeling studies. J. Agric. Food Chem. 2010, 58, 11876-11882. [CrossRef] [PubMed]

36. López-García, M.Á.; López, Ó.; Maya, I.; Fernández-Bolaños, J.G. Complexation of hydroxytyrosol with $\beta$-cyclodextrins. An efficient photoprotection. Tetrahedron 2010, 66, 8006-8011. [CrossRef]

37. Kotronia, M.; Kavetsou, E.; Loupassaki, S.; Kikionis, S.; Vouyiouka, S.; Detsi, A. Encapsulation of Oregano (Origanum onites L.) essential oil in $\beta$-cyclodextrin ( $\beta-C D)$ : Synthesis and characterization of the inclusion complexes. Bioengineering $2017,4,74$. [CrossRef]

38. Guinesi, L.S.; Cavalheiro, É.T.G. The use of DSC curves to determine the acetylation degree of chitin/chitosan samples. Thermochim. Acta 2006, 444, 128-133. [CrossRef]

39. Chatzidaki, M.; Kostopoulou, I.; Kourtesi, C.; Pitterou, I.; Avramiotis, S.; Xenakis, A.; Detsi, A. $\beta$-Cyclodextrin as carrier of novel antioxidants: A structural and efficacy study. Colloids and Surfaces A: Physicochem. Eng. Asp. 2020, 603, 125262. [CrossRef]

40. De Pinho Neves, A.L.; Milioli, C.C.; Müller, L.; Riella, H.G.; Kuhnen, N.C.; Stulzer, H.K. Factorial design as tool in chitosan nanoparticles development by ionic gelation technique. Colloids Surf. A Physicochem. Eng. Asp. 2014, 445, 34-39. [CrossRef]

41. Abarca, R.L.; Rodríguez, F.J.; Guarda, A.; Galotto, M.J.; Bruna, J.E. Characterization of beta-cyclodextrin inclusion complexes containing an essential oil component. Food Chem. 2016, 196, 968-975. [CrossRef] [PubMed]

42. Benesi, H.A.; Hildebrand, J.H.J. A spectrophotometric investigation of the interaction of iodine with aromatic hydrocarbons. J. Am. Chem. Soc. 1949, 71, 2703-2707. [CrossRef] 
43. Islam, M.M.; Chakraborty, M.; Pandya, P.; Al Masum, A.; Gupta, N.; Mukhopadhyay, S. Binding of DNA with Rhodamine B: Spectroscopic and molecular modeling studies. Dye. Pigment. 2013, 99, 412-422. [CrossRef]

44. Al Masum, A.; Chakraborty, M.; Ghosh, S.; Laha, D.; Karmakar, P.; Islam, M.M.; Mukhopadhyay, S. Biochemical activity of a fluorescent dye rhodamine 6G: Molecular modeling, electrochemical, spectroscopic and thermodynamic studies. J. Photochem. Photobiol. B Biol. 2016, 164, 369-379. [CrossRef]

45. Sayed, M.; Gubbala, G.K.; Pal, H. Contrasting interactions of DNA-intercalating dye acridine orange with hydroxypropyl derivatives of $\beta$-cyclodextrin and $\gamma$-cyclodextrin hosts. New J. Chem. 2019, 43, 724-736. [CrossRef] 